UCRL-ID-134649

\title{
Surface Topographies of One-Year Weight-Loss Coupons of Alloy C-22 from Long-Term Corrosion Testing
}

Peter J. Bedrossian

June 11, 1999

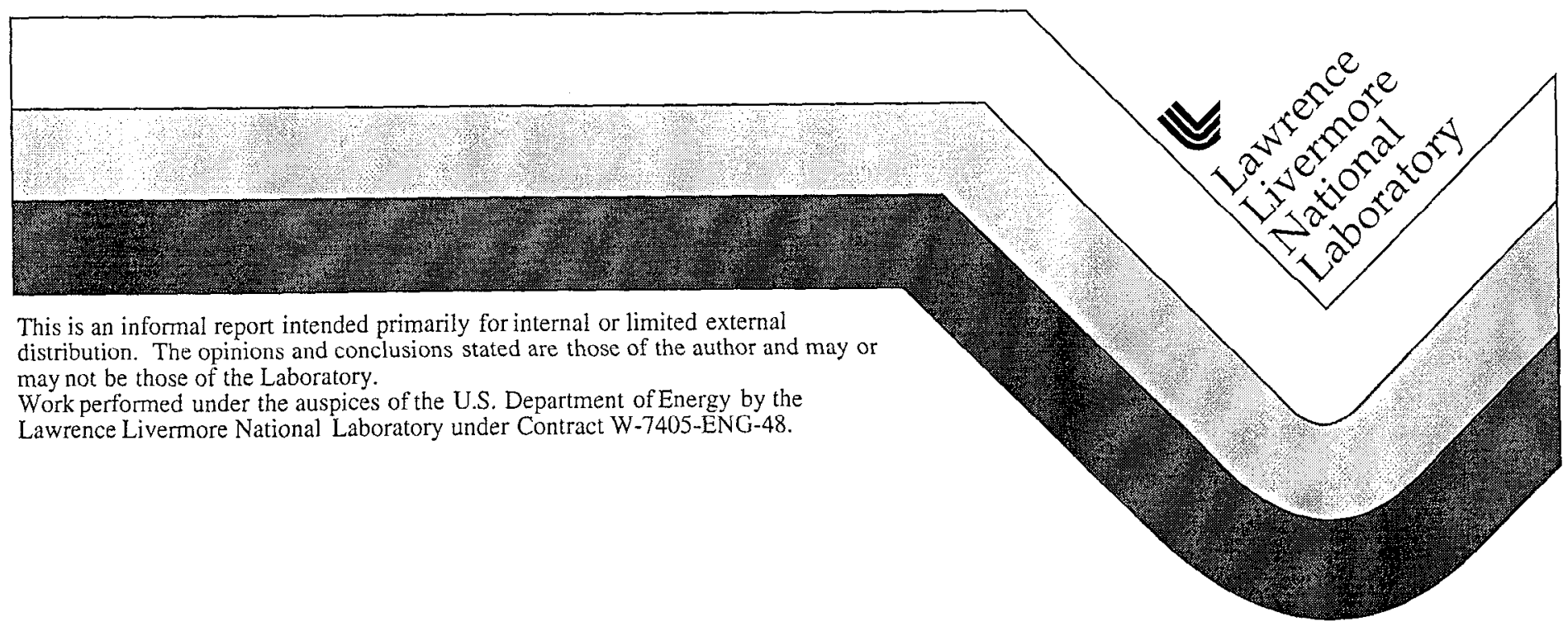




\section{DISCLAIMER}

This document was prepared as an account of work sponsored by an agency of the United States Government. Neither the United States Government nor the University of California nor any of their employees, makes any warranty, express or implied, or assumes any legal liability or responsibility for the accuracy, completeness, or usefulness of any information, apparatus, product, or process disclosed, or represents that its use would not infringe privately owned rights. Reference herein to any specific commercial product, process, or service by trade name, trademark, manufacturer, or otherwise, does not necessarily constitute or imply its endorsement, recommendation, or favoring by the United States Government or the University of California. The views and opinions of authors expressed herein do not necessarily state or reflect those of the United States Government or the University of California, and shall not be used for advertising or product endorsement purposes.

This report has been reproduced directly from the best available copy.

Available to DOE and DOE contractors from the Office of Scientific and Technical Information

P.O. Box 62, Oak Ridge, TN 37831

Prices available from (615) 576-8401, FTS 626-8401

Available to the public from the

National Technical Information Service

U.S. Department of Commerce

5285 Port Royal Rd.,

Springfield, VA 22161 


\title{
Surface Topographies \\ of \\ One-Year Weight-Loss Coupons of Alloy C-22 \\ from \\ Long-Term Corrosion Testing
}

\author{
Peter J. Bedrossian \\ Division of Materials Science \& Technology \\ Lawrence Livermore National Laboratory, Livermore CA 94551
}

11 June 1999

\begin{abstract}
We have used an atomic force microscope (AFM) to characterize the surface topographies of weight-loss coupons of Alloy C-22 which had been exposed to two different environments in the Long-Term Corrosion Test Facility at LLNL for one year. We have observed a silicate deposit on these coupons, with the most extensive coverage occuring on the coupon immersed in an acidified bath. We have not detected localized corrosion on these coupons.
\end{abstract}

\section{Introduction}

The Long-Term Corrosion Test Facility (LTCTF) at LLNL is an array of tanks holding various aqueous baths with controlled electrolyte concentrations at 60 or $90^{\circ} \mathrm{C}$, in which coupons of candidate materials for the Waste Package are held in either aqueous (below the water line) or vapor (above the water line) phase conditions and removed periodically for analysis. Although the LTCTF coupons have primarly been used for analysis of general corrosion via weight loss, the objective of the present study has been the search for signs of localized corrosion, if any. The "weight loss" coupons are 2 inches long, 1 inch wide, and 1/8 inch thick. Descriptions of the LTCTF and its uses, along with the detailed composition of the aqueous environments, are contained in Reference [1].

The atomic force microscope (AFM), with sub-nanometer vertical resolution, is an ideal tool for detecting pit initiation in localized areas. We have applied AFM to five "weight loss" coupons of Alloy C-22: one control which was never in any bath (DWA163), one aqueous phase sample from an acidified well water, SAW (DWA051), one vapor phase sample from SAW (DWA048), one aqucous phase sample from an alkaline water, SCW (DWA120) and one vapor phase sample from SCW (DWA117). The coupon numbers are official designations of the Yucca Mountain Program (YMP), and the data file numbers correspond to the designations which will be incorporated in the YMP Technical Data Management System. The composition of Alloy C-22 is contained in Reference [2].

\section{Results and Discussion}

Representative AFM data are collected and displayed below. Each set of data consists of a large-area scan of at least $25 \times 25 \mu \mathrm{m}$ followed by smaller-area details of the region 
displayed in the large-area scan. We have used a Digital Instruments DM3100 AFM. After the coupons were removed from the LTCTF, they were ultrasonically agitated in deionized water, acetone, and methanol for ten minutes each.

The gross surface topography of the weight-loss coupons is dominated by the machining grooves, with typical heights of several hundred nanometers and typical lateral periodicities of several microns. The machining features on a bare surface are plainly visible on the images of coupon DWA163. Those samples which were removed from the LTCTF exhibit varying degrees of coverage by a deposit on top of this gross topography.

$\mathrm{X}$-ray diffraction scans of all five coupons show that the deposit is predominantly a silicate or $\mathrm{SiO}_{2}$, with some $\mathrm{NaCl}$ appearing on the two samples which were in the SAW tank. The AFM images show that the most extensive coverage of the deposit occured on test coupon DWA051, which was immersed in the SAW bath. The next most extensive coverage occured on test coupon DWA048, which was held above the water line in the SAW bath. The two test coupons removed from the SCW bath showed lesser degrees of coverage by the silicate deposit in both the AFM images and the X-ray diffraction scans.

Incomplete surface coverage by the silicate deposit often results in the appearance of holes in surface, particularly on the DWA051 coupon. We believe that the data collected to date to not show any of these holes extending below the surface of the metal, because the bottoms of the holes are typically flat. One illustration of the analysis leading to this conclusion is shown below in the profile measured along the line trace marked in the image pb990607.023, which spans two such holes. As shown in the profile, the bottoms of the holes are flat, as would be expected for an interruption that occurs only in the silicate deposit.

The following data are presented in this report, with page numbers listed:

DWA163 (Control Coupon) .......................................................4

pb990607.019 AFM Image ..................................................... 4

pb990607.020 AFM Image ..................................................... 5

pb990607.021 AFM Image ...................................................... 6

pb990607.022 AFM Image ........................................................... 7

SAW Test Coupons............................................................... 8

X-Ray Spectra of scales on SAW Coupons........................................ 8

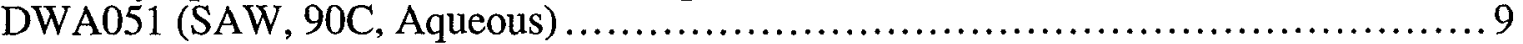

pb990607.023 AFM Image ................................................... 9

pb990607.023 AFM Image, top view .......................................... 10

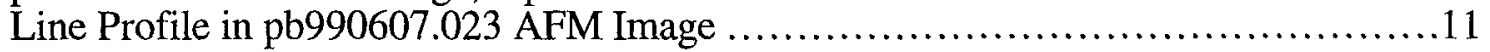

pb990607.024 AFM Image ......................................................... 12

pb990607.025 AFM Image ......................................................... 13

pb990607.033 AFM Image ........................................................ 14

pb990607.029 AFM Image ...................................................... 15

pb990607.030 AFM Image ....................................................... 16

pb990607.031 AFM Image ..................................................... 17

pb990607.032 AFM Image .................................................... 18

pb990607.032 AFM Image .................................................... 19

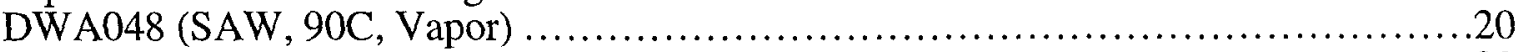

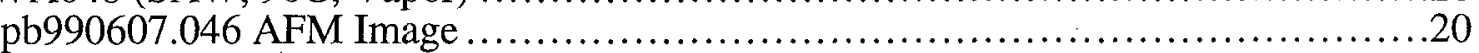

pb990607.045 AFM Image .....................................................21

pb990607.048 AFM Image ...........................................................22

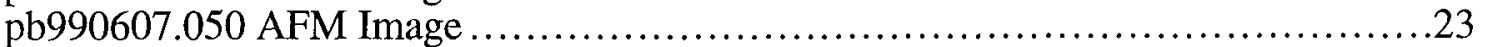

pb990607.054 AFM Image ..................................................... 24

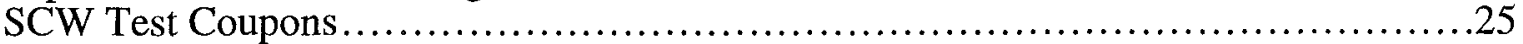

X-Ray Spectra of Scales on SCW Test Coupons ................................. 25

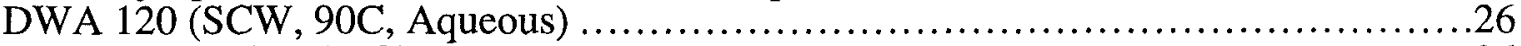

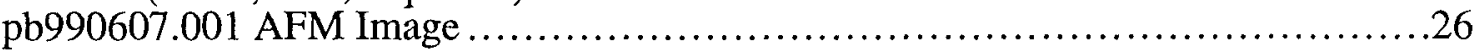


pb990607.005 AFM Image .......................................................27

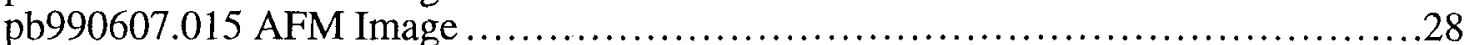

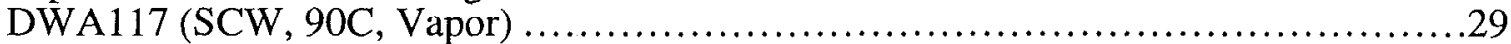

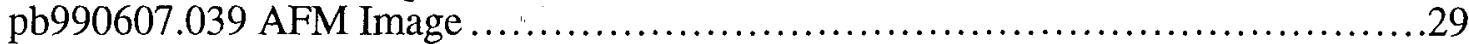

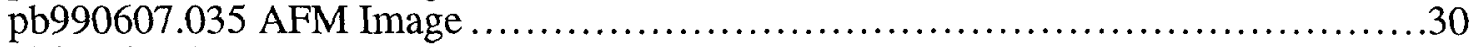

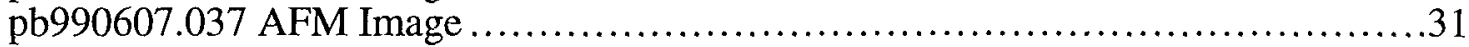

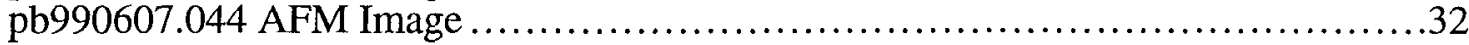

pb990607.041 AFM Image ..................................................... 33

pb990607.042 AFM Image ................................................. 34

\section{Summary}

A study of four test coupons of Alloy $\mathrm{C}-22$ removed from the LTCTF after one year showed varying degrees of coverage by silicate deposits but no evidence of localized corrosion by pitting.

\section{Acknowledgments}

The author is grateful to David Fix for his extensive AFM data collection, to Dominic Delgiudice for the X-ray measurements, to John Estill and Kenneth King for providing samples from the LTCTF, and to Joseph Farmer, Daniel McCright, and Ronald Musket for helpful discussions. This work was conducted at LLNL under the auspices of the US Department of Energy under Contract W-7405-Eng-48, and was supported by the Yucca Mountain Program.

I J C Farmer, et al., "Development of Integrated Meghanistically-Based Degradation-Mode Models for Performance Assessment of High-Level Waste Containers," UCRL-ID-130811 (1998), pp. 3 and 49.

${ }^{2}$ L Corb, et al, ed., ASM Handbook, Volume 13: Corrosion. (Metals Park: ASM International, 1987), p. 644 . 


\section{DWA163 (Control Coupon)}

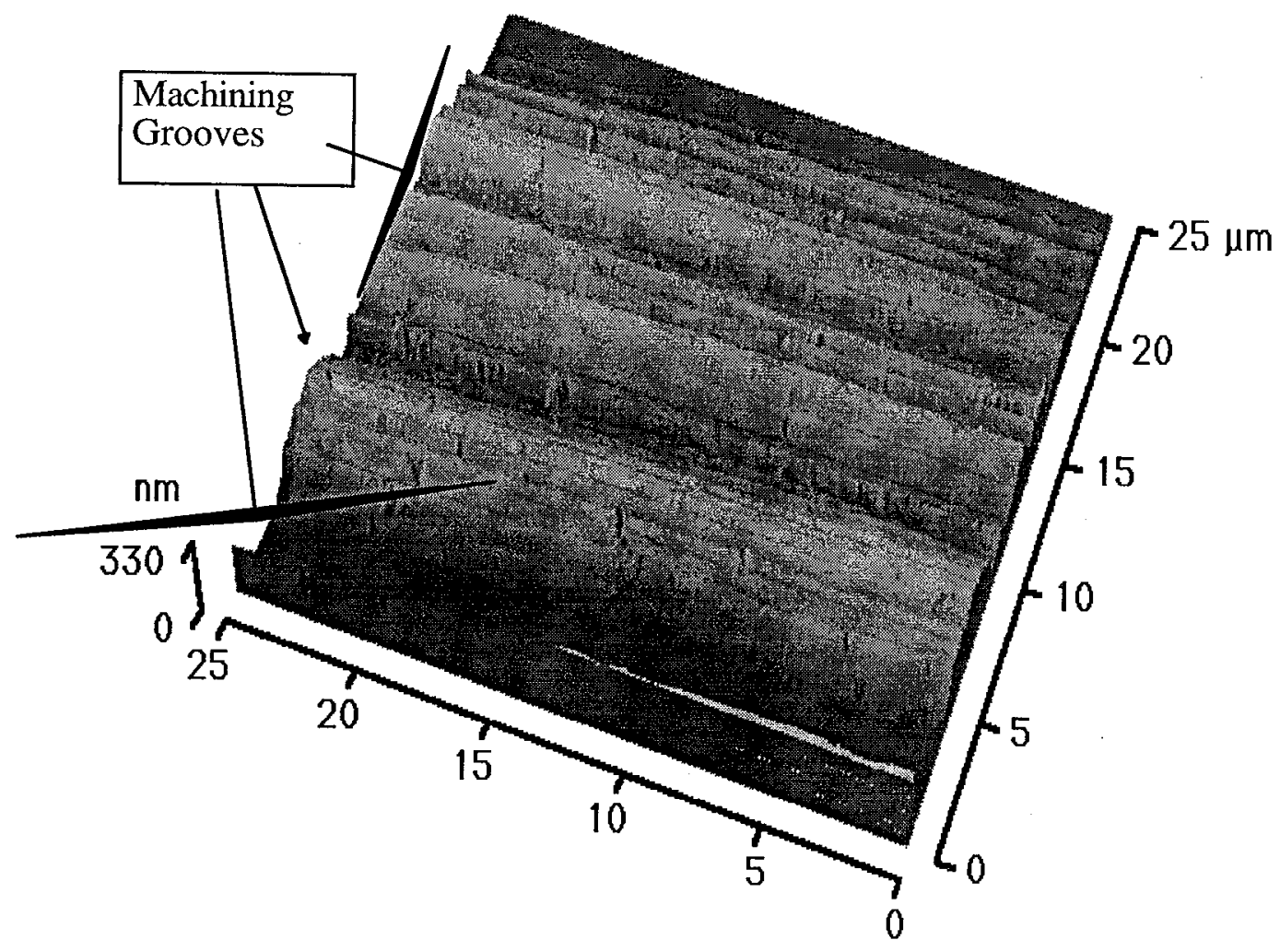

pb990607.019 AFM Image 


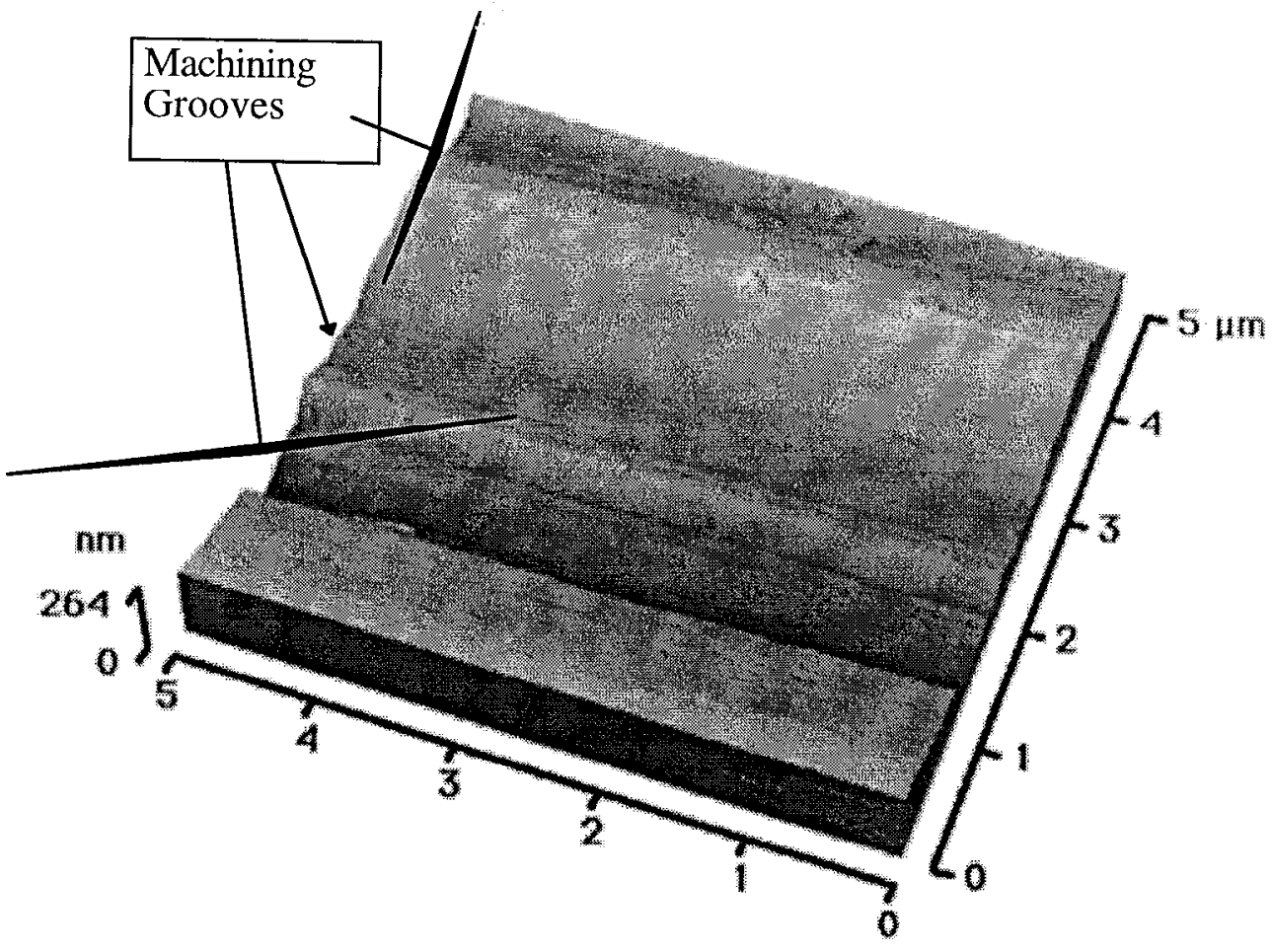

pb990607.020 AFM Image 


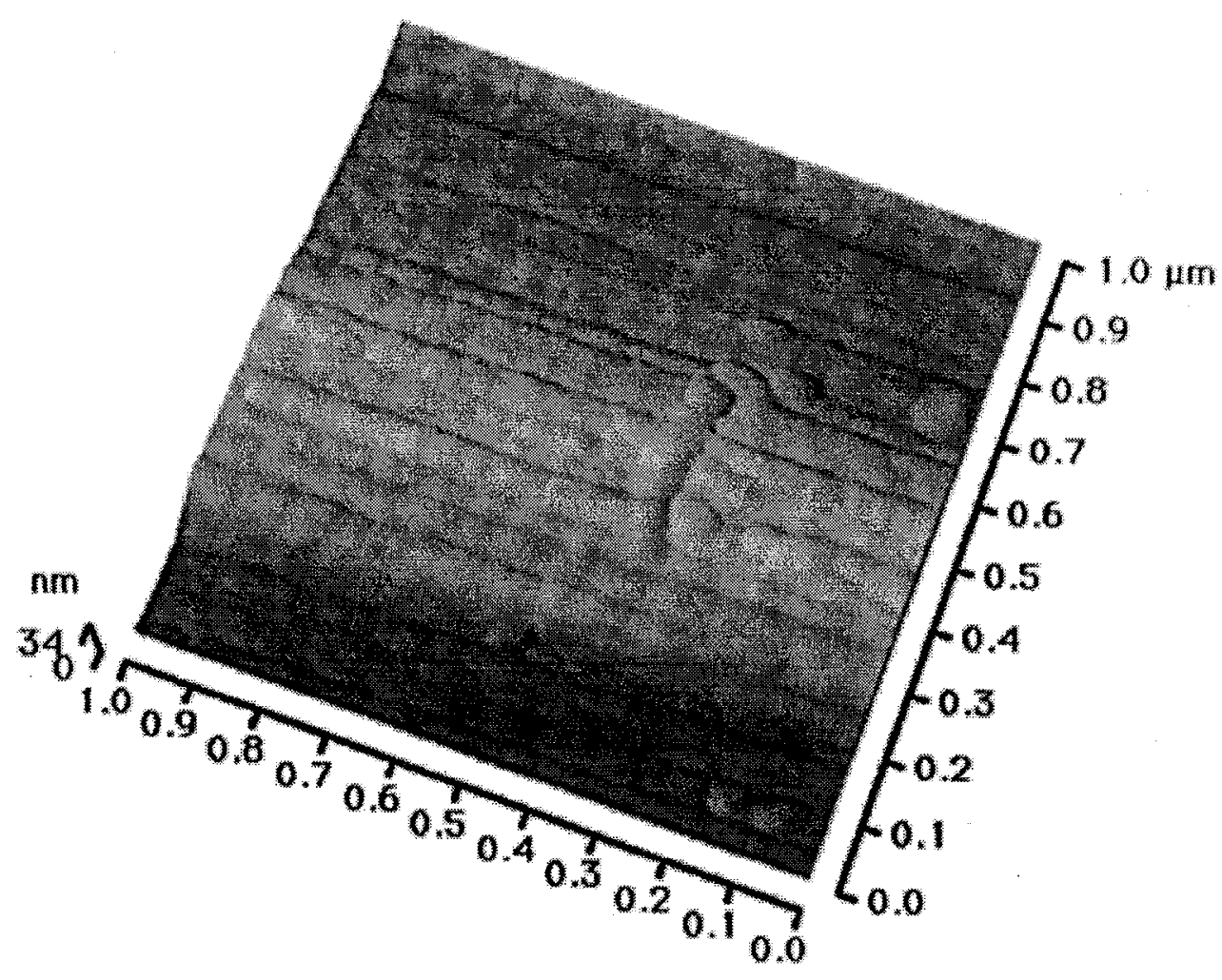

pb990607.021 AFM Image 


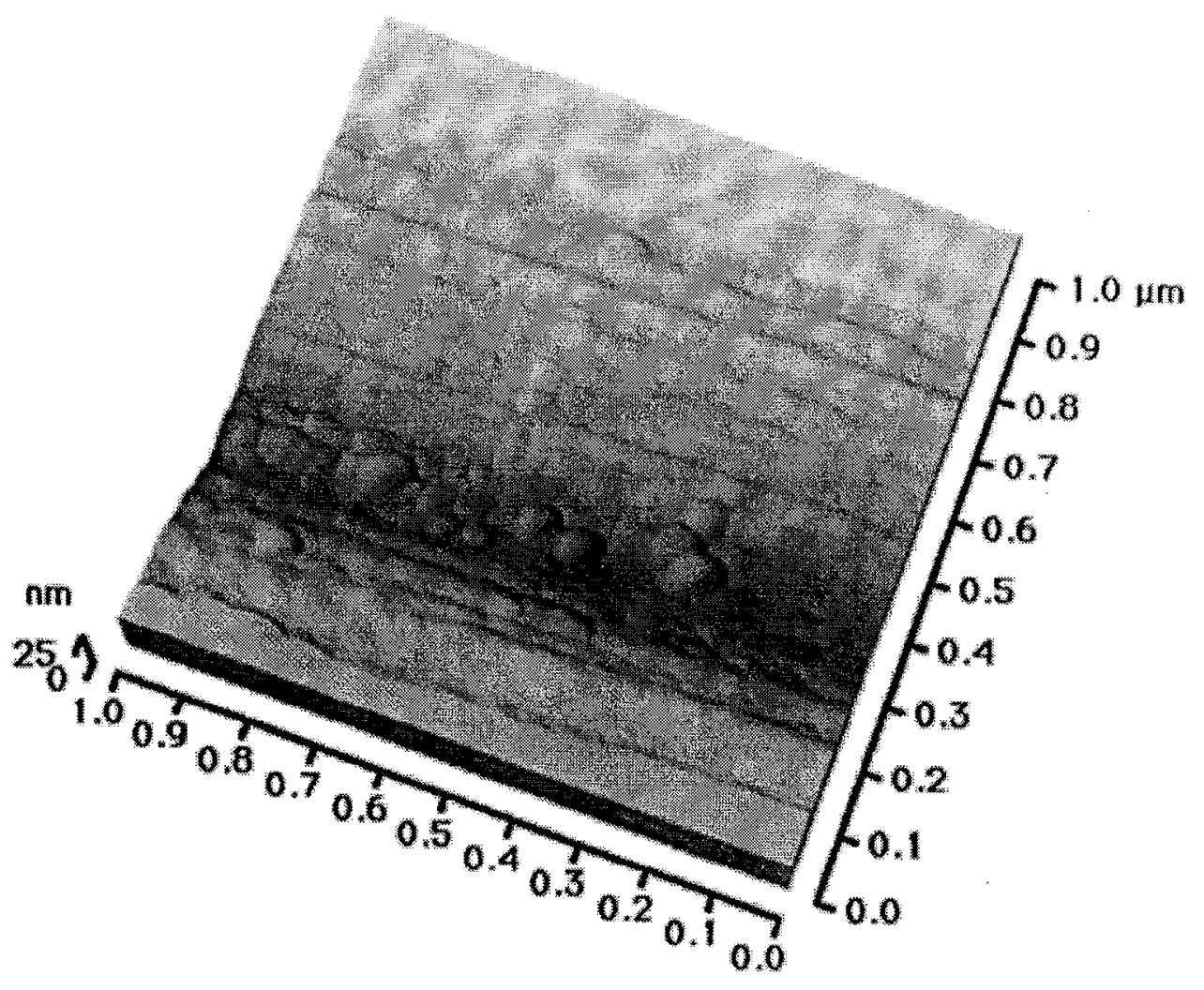

pb990607.022 AFM Image 
SAW Test Coupons

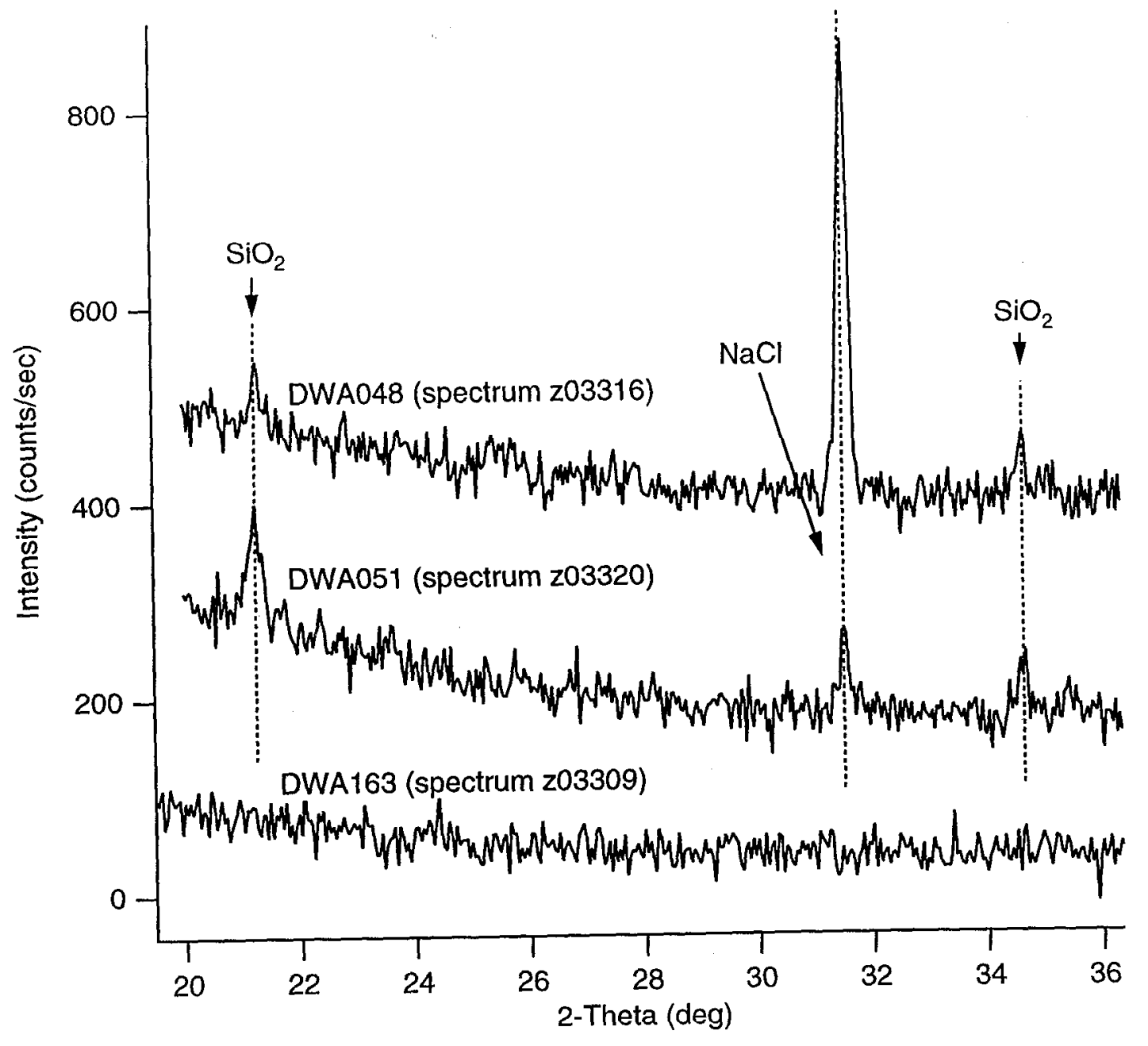

X-Ray Spectra of scales on SAW Coupons 


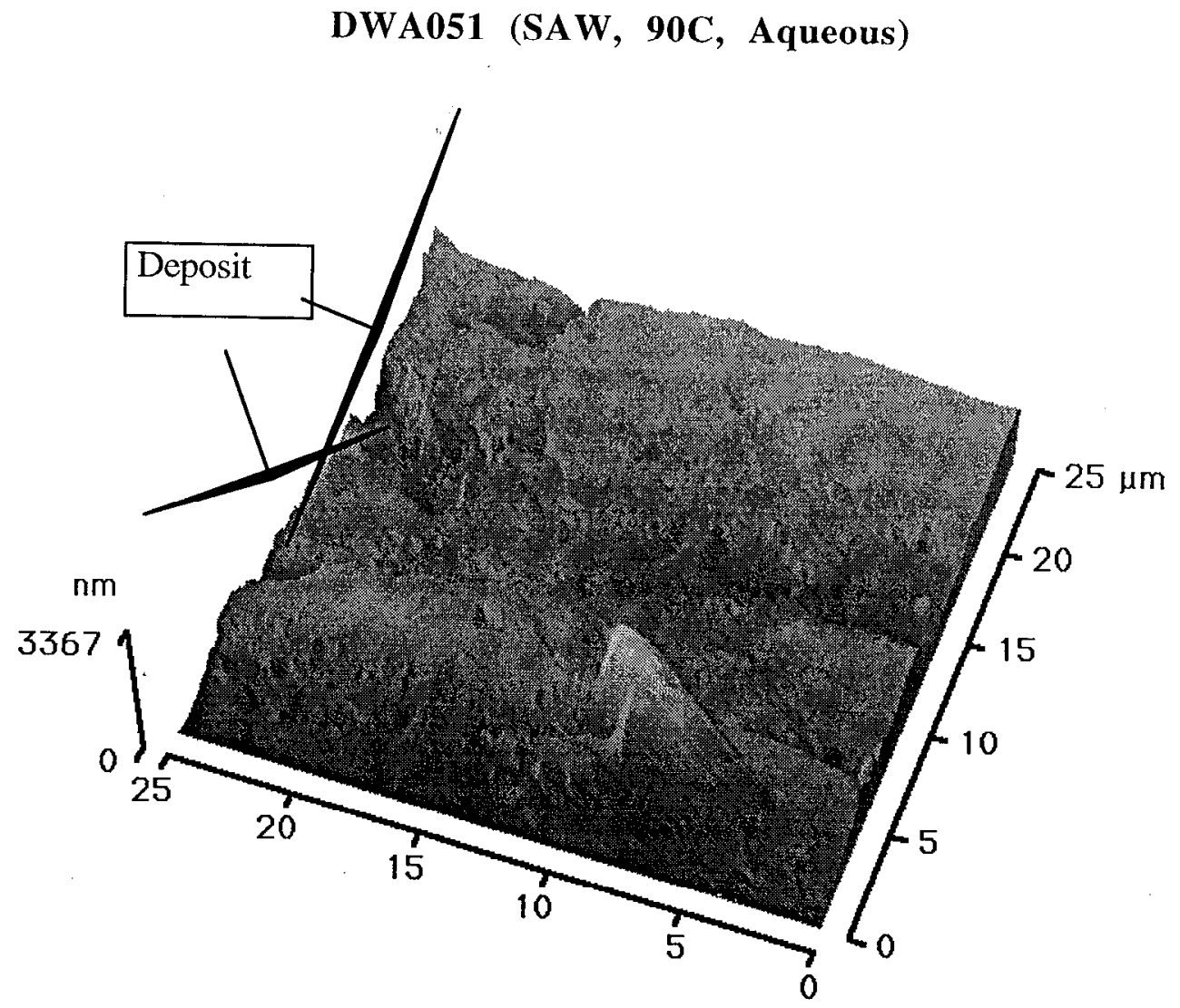

pb990607.023 AFM Image 


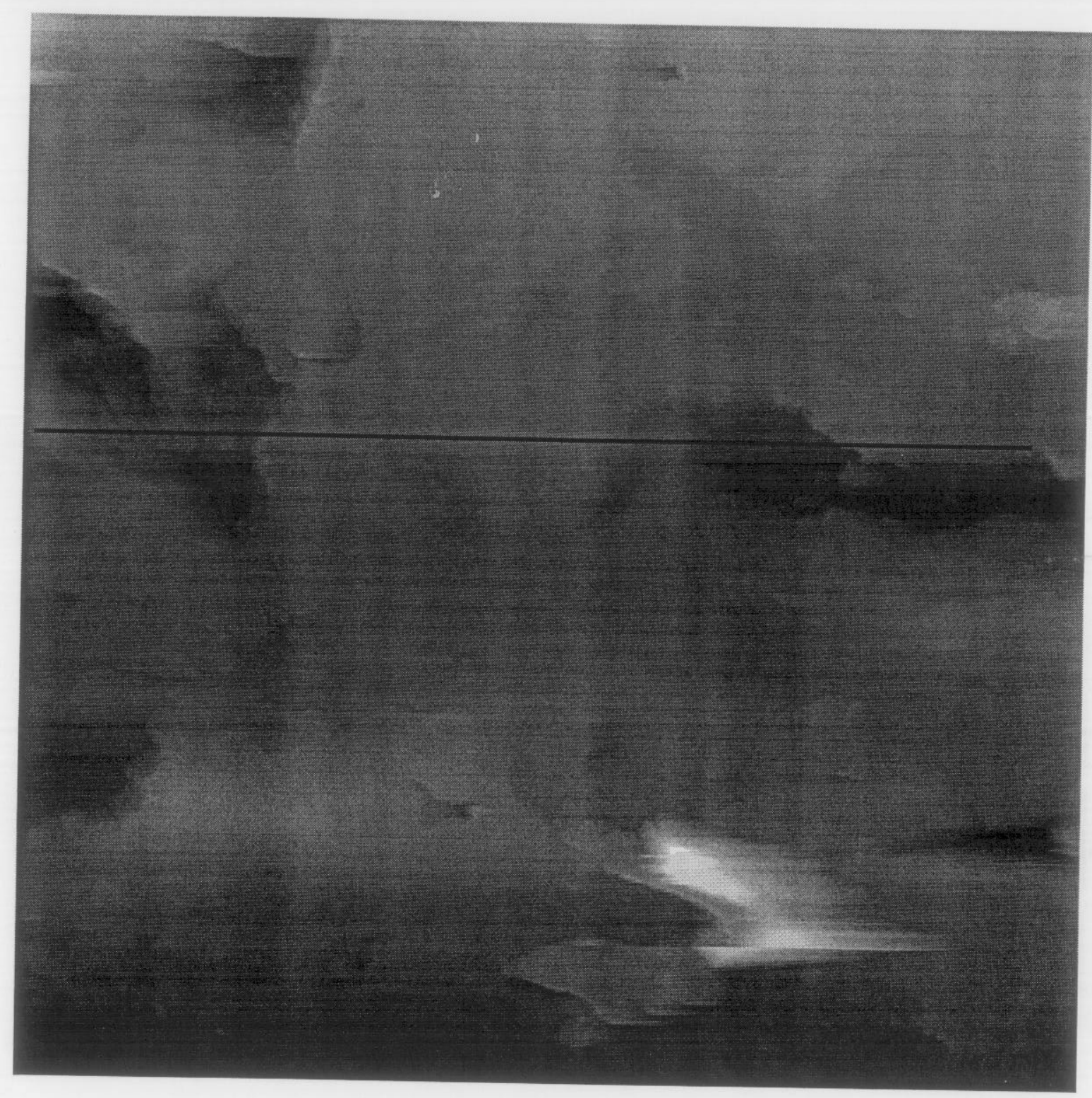

pb990607.023 AFM Image, top view 


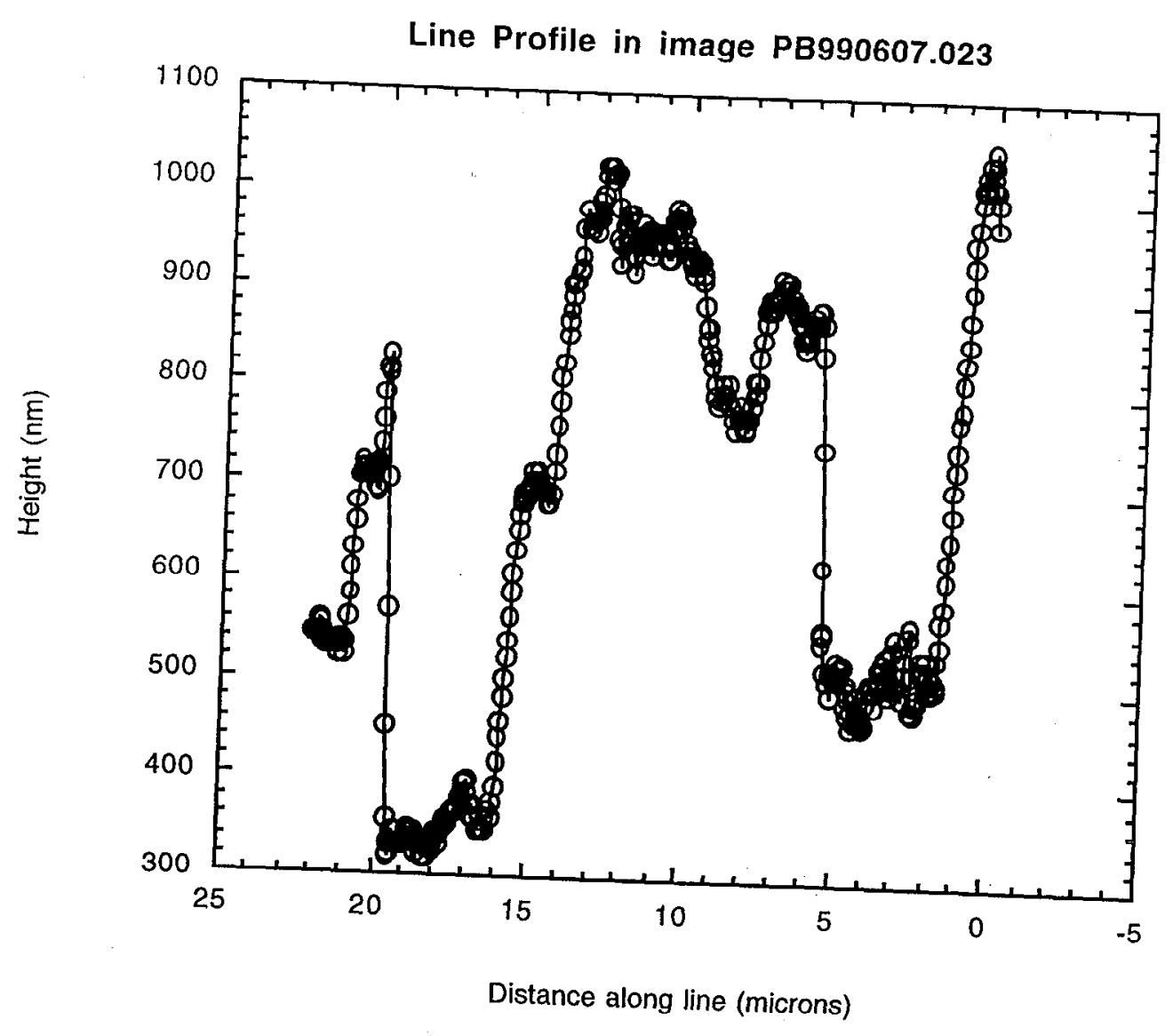

Line Profile in pb990607.023 AFM Image 


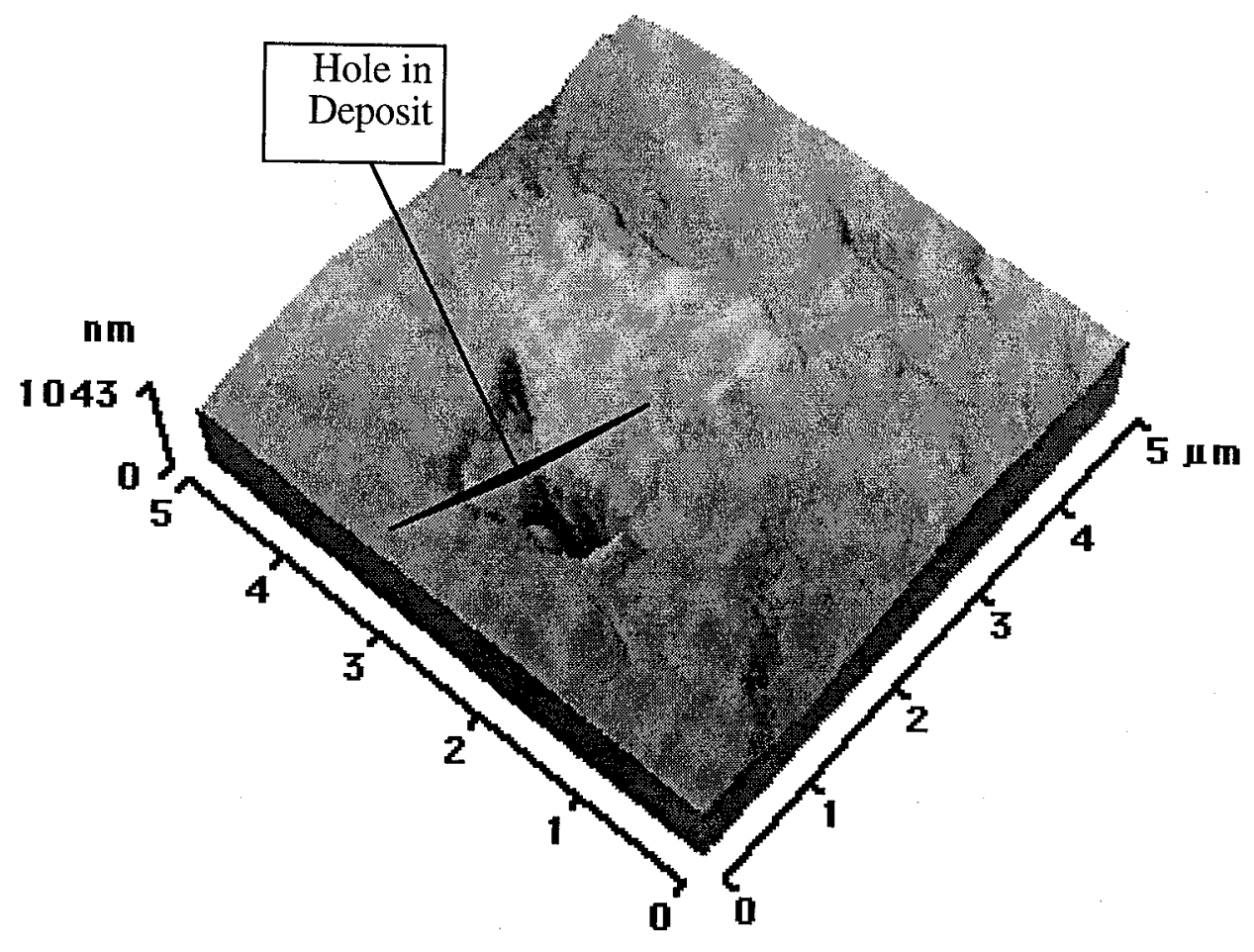

pb990607.024 AFM Image 


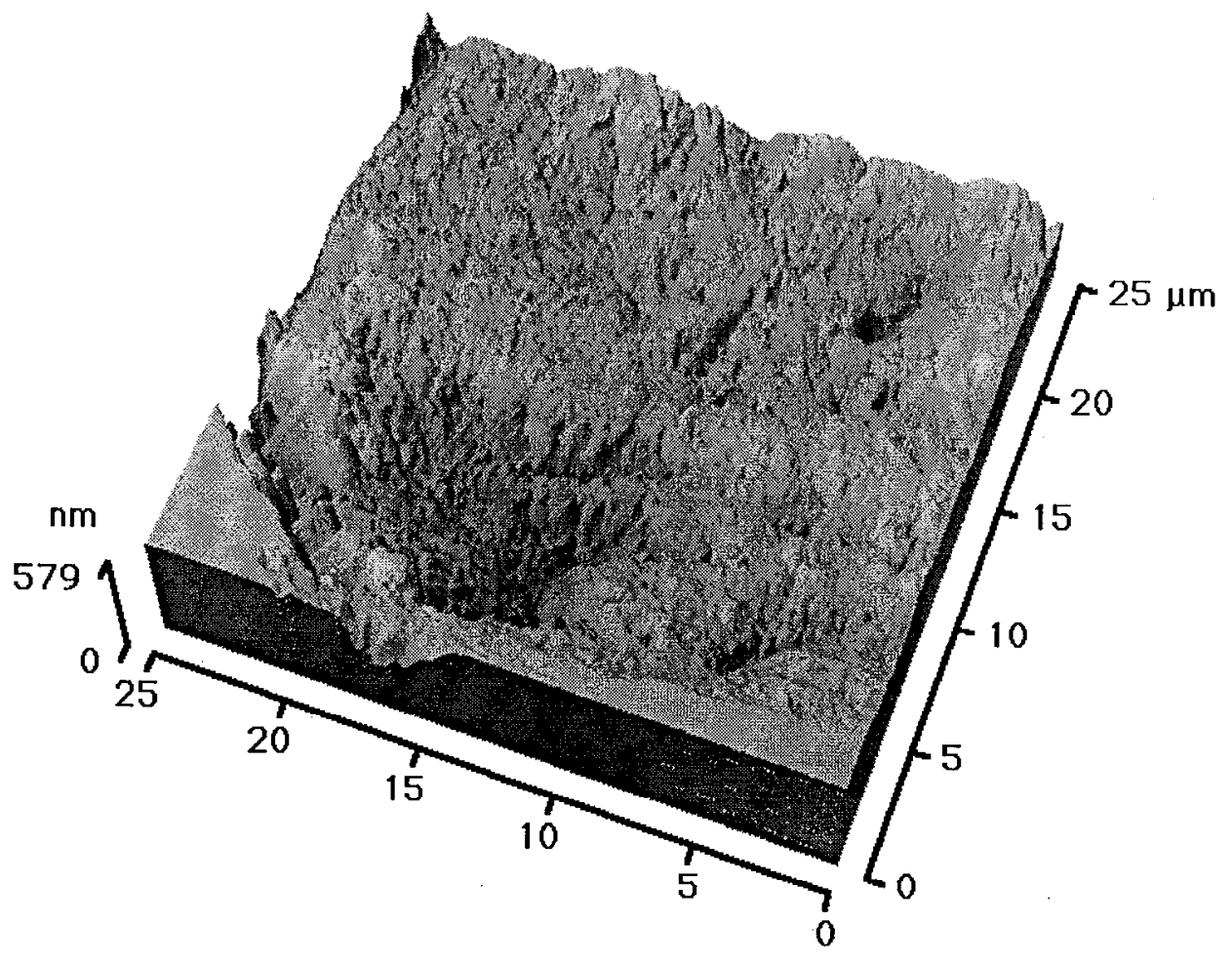

pb990607.025 AFM Image 


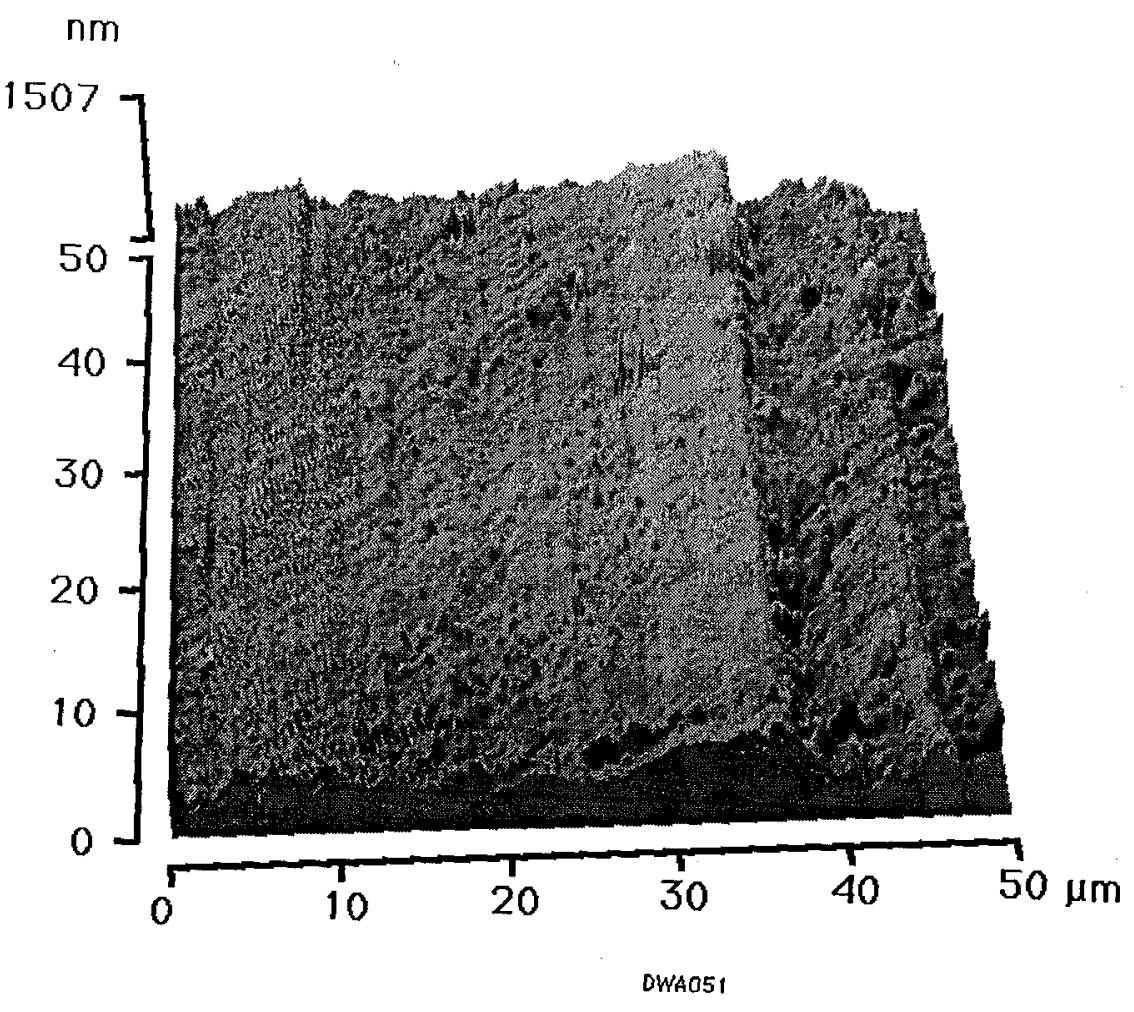

pb990607.033 AFM Image 


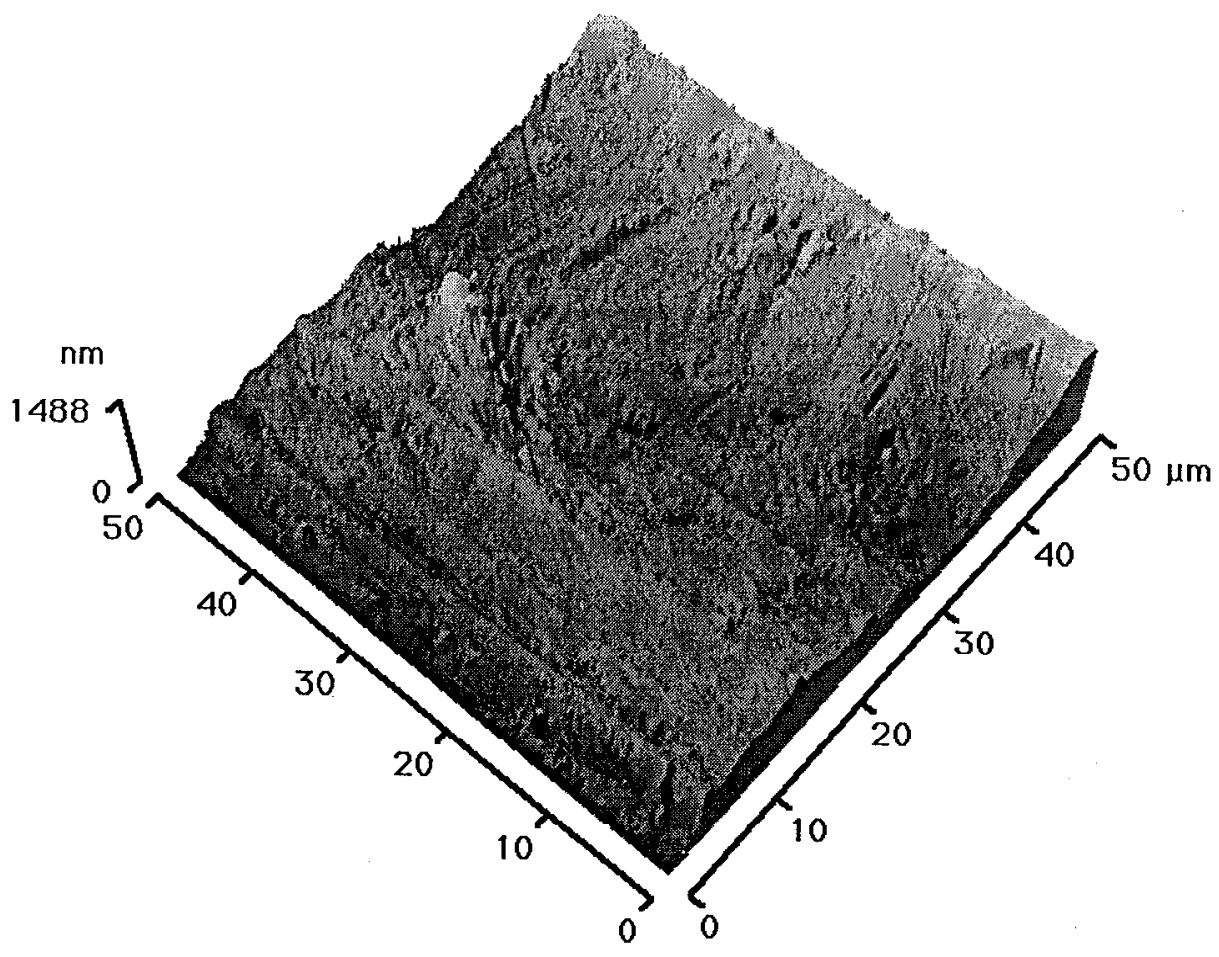

pb990607.029 AFM Image 


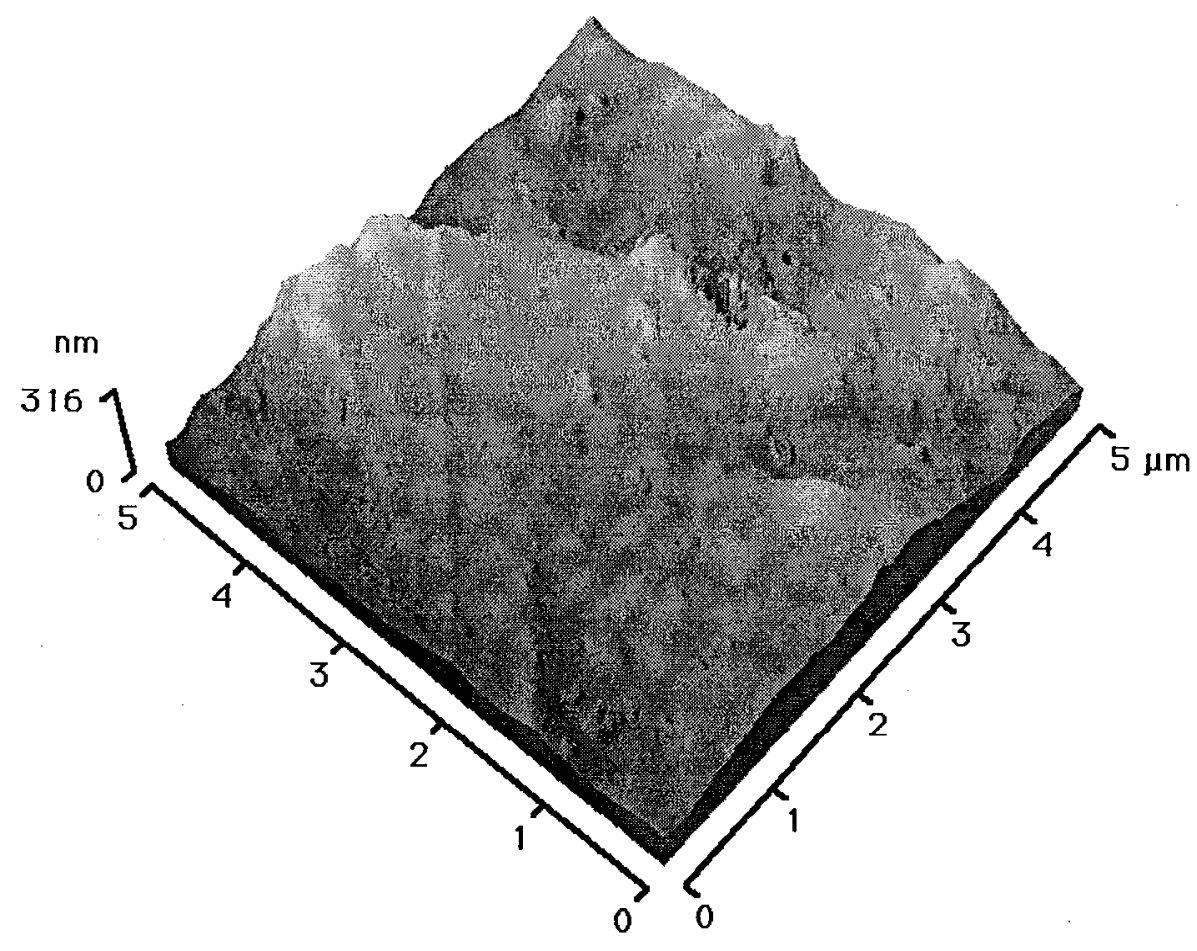

pb990607.030 AFM Image 


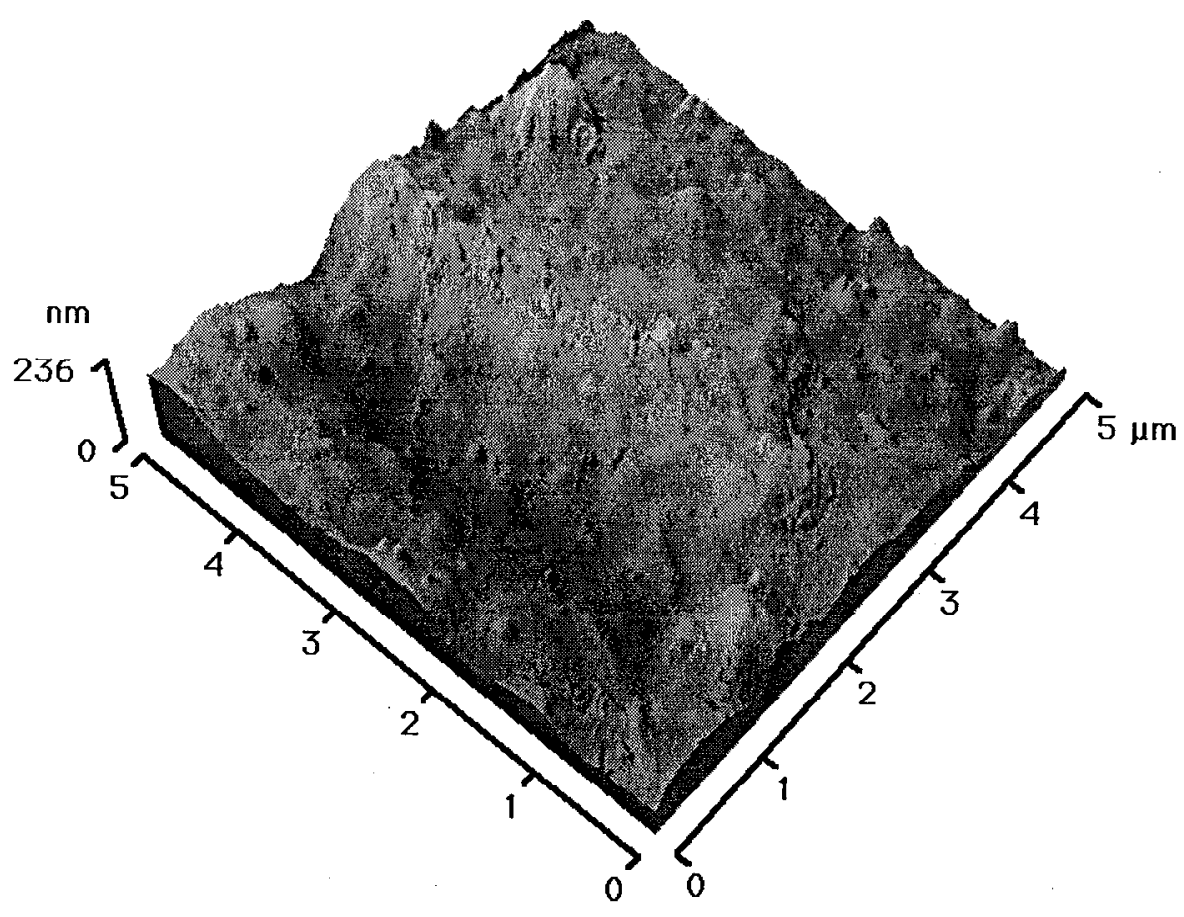

pb990607.031 AFM Image 


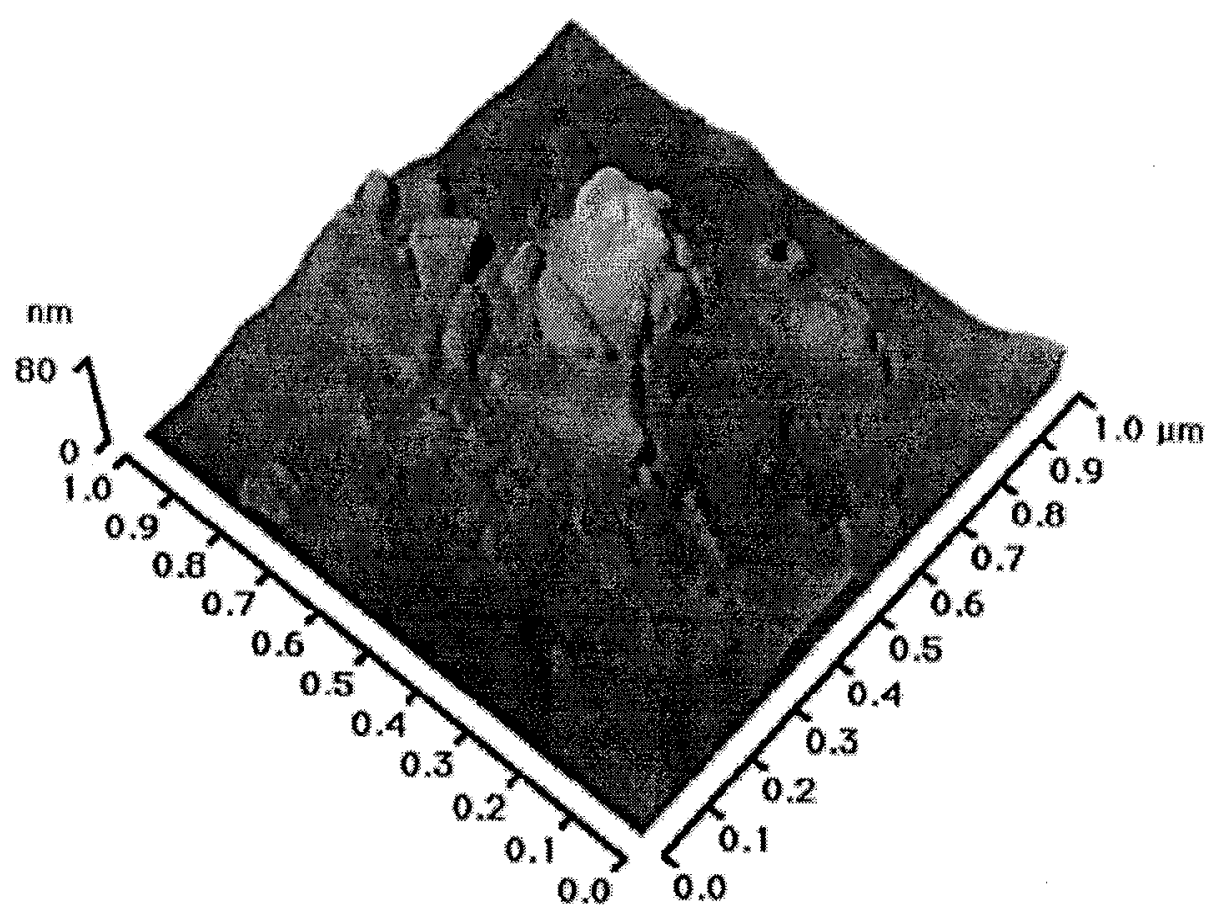

pb990607.032 AFM Image 


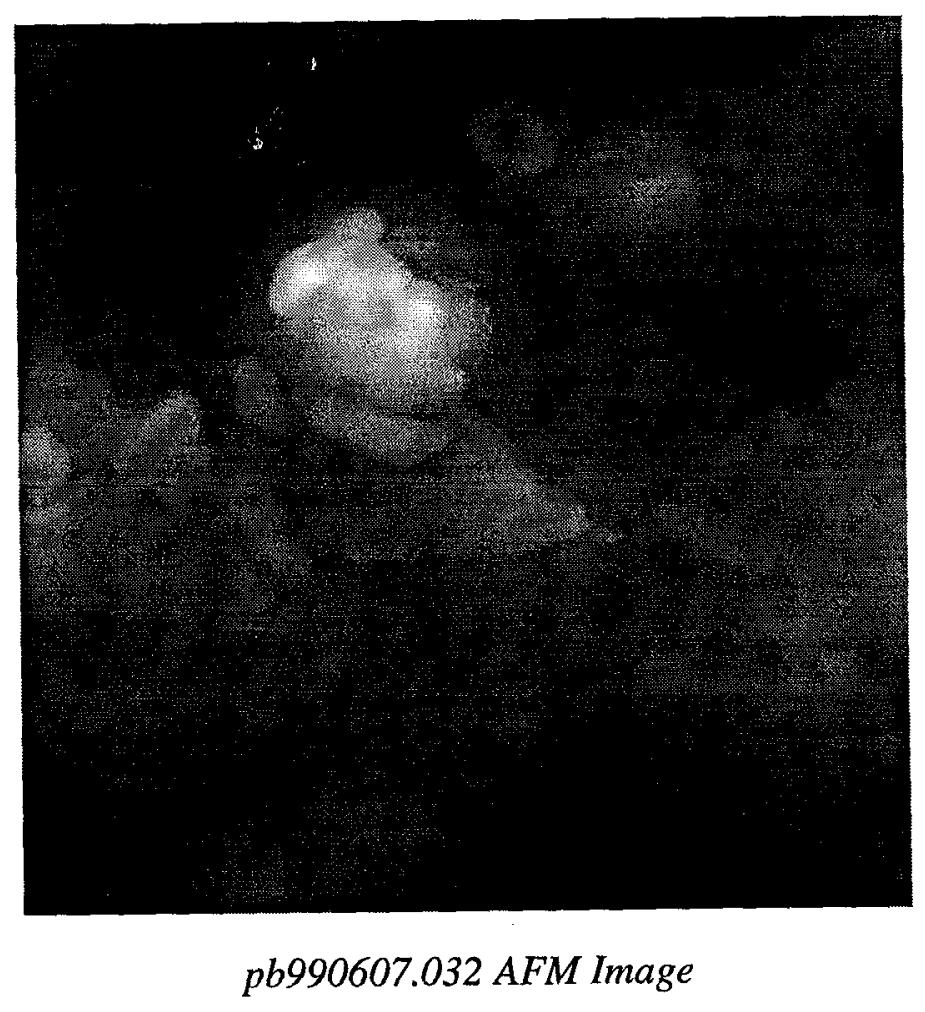


DWA048 (SAW, 90C, Vapor)

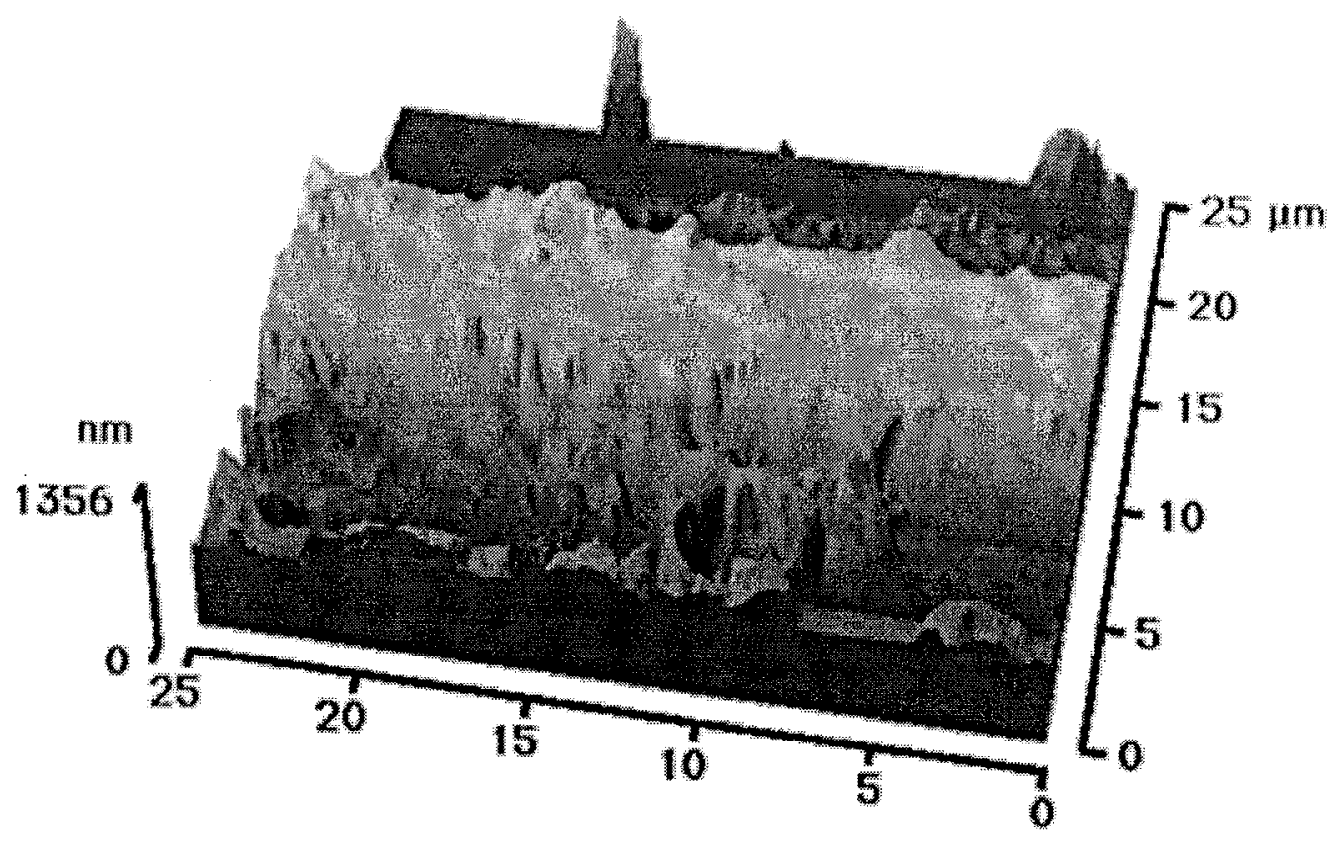

pb990607.046 AFM Image 


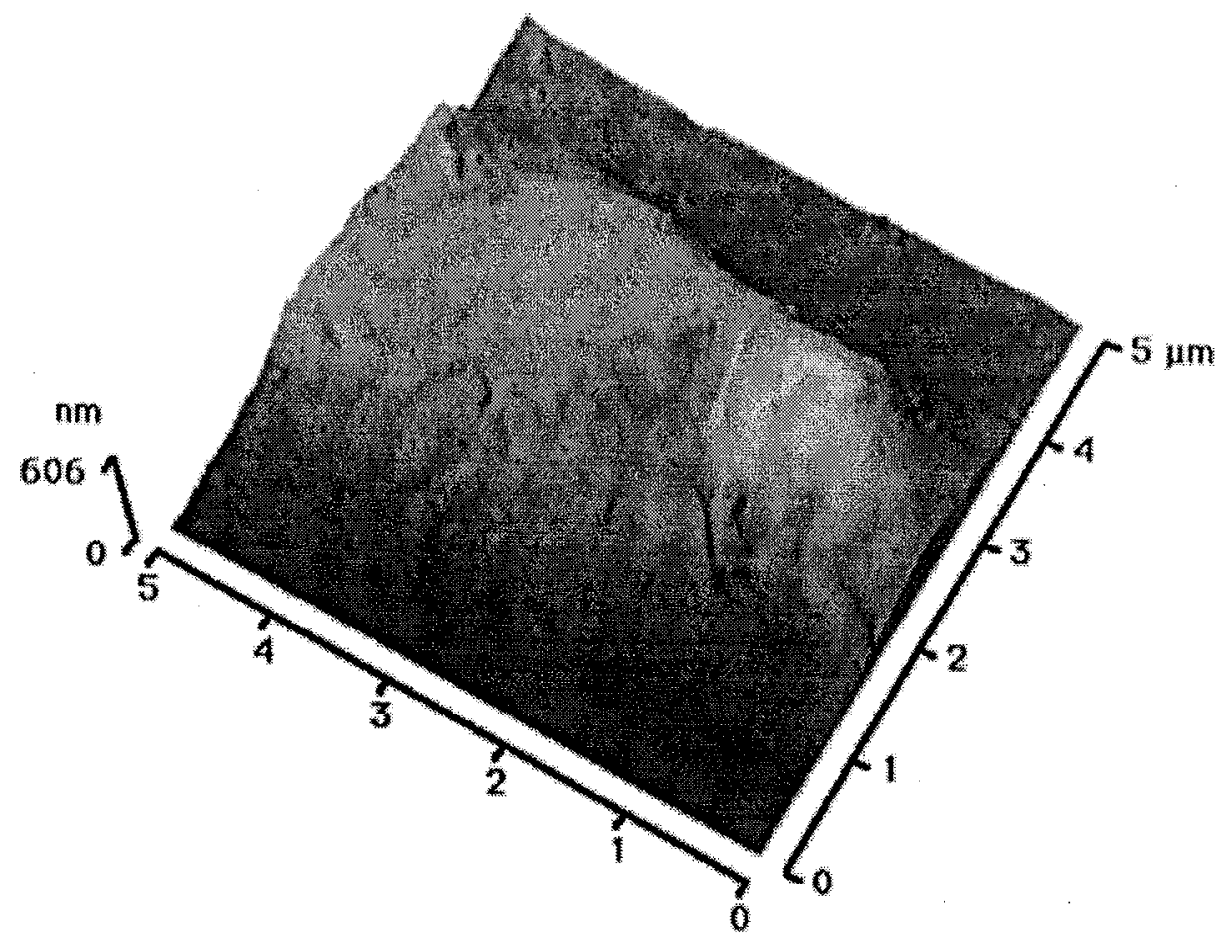

pb990607.045 AFM Image 


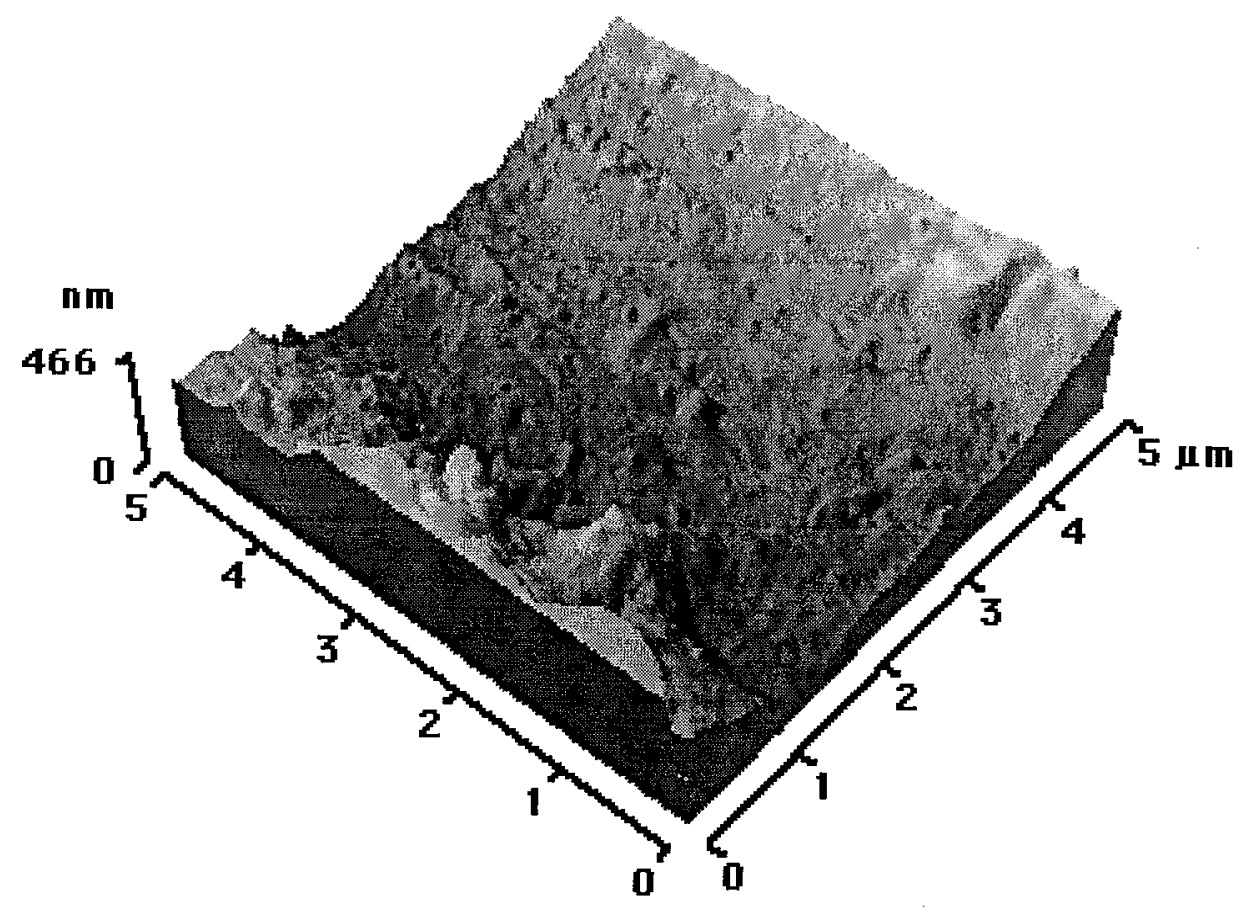

pb990607.048 AFM Image 


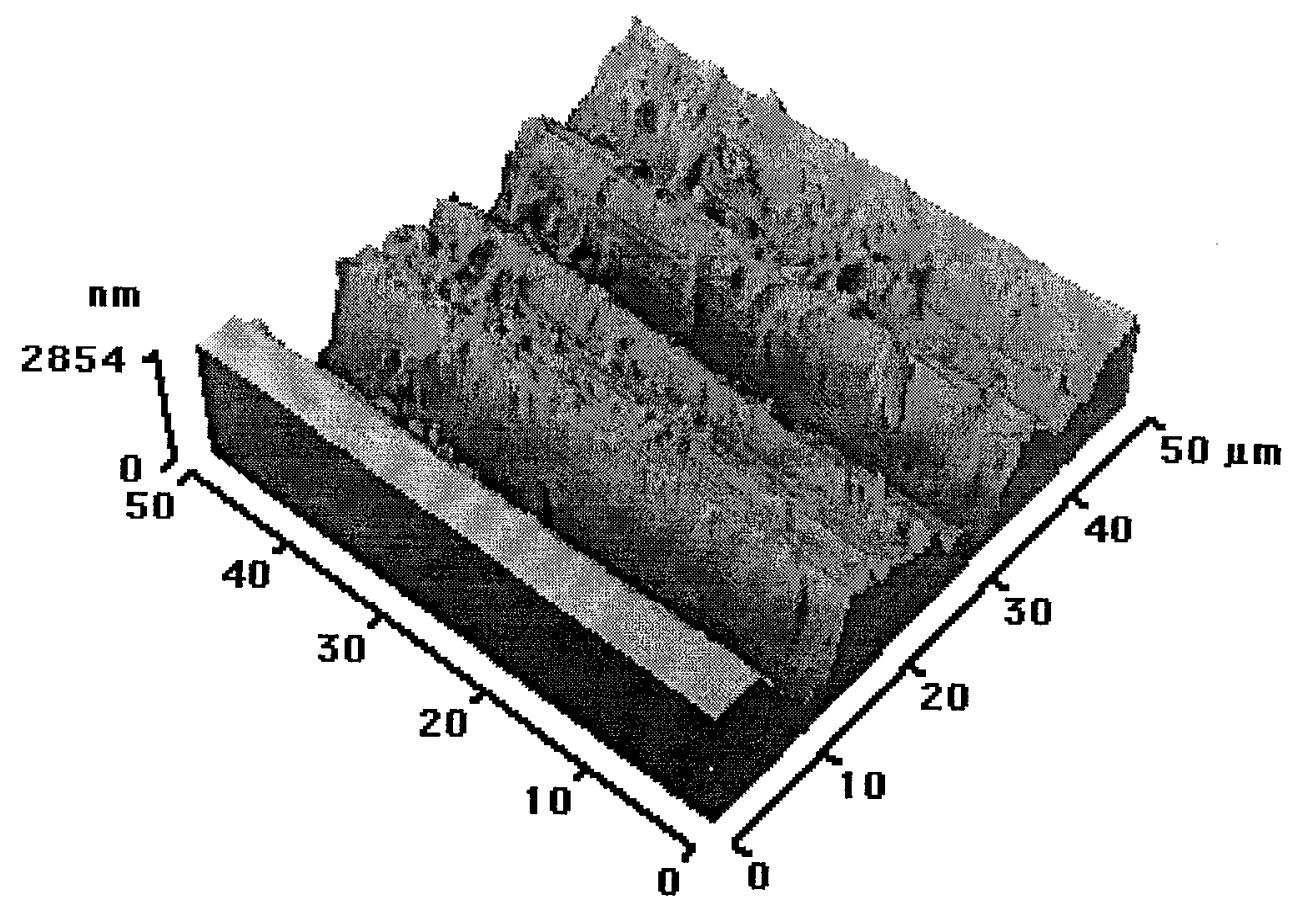

pb990607.050 AFM Image 


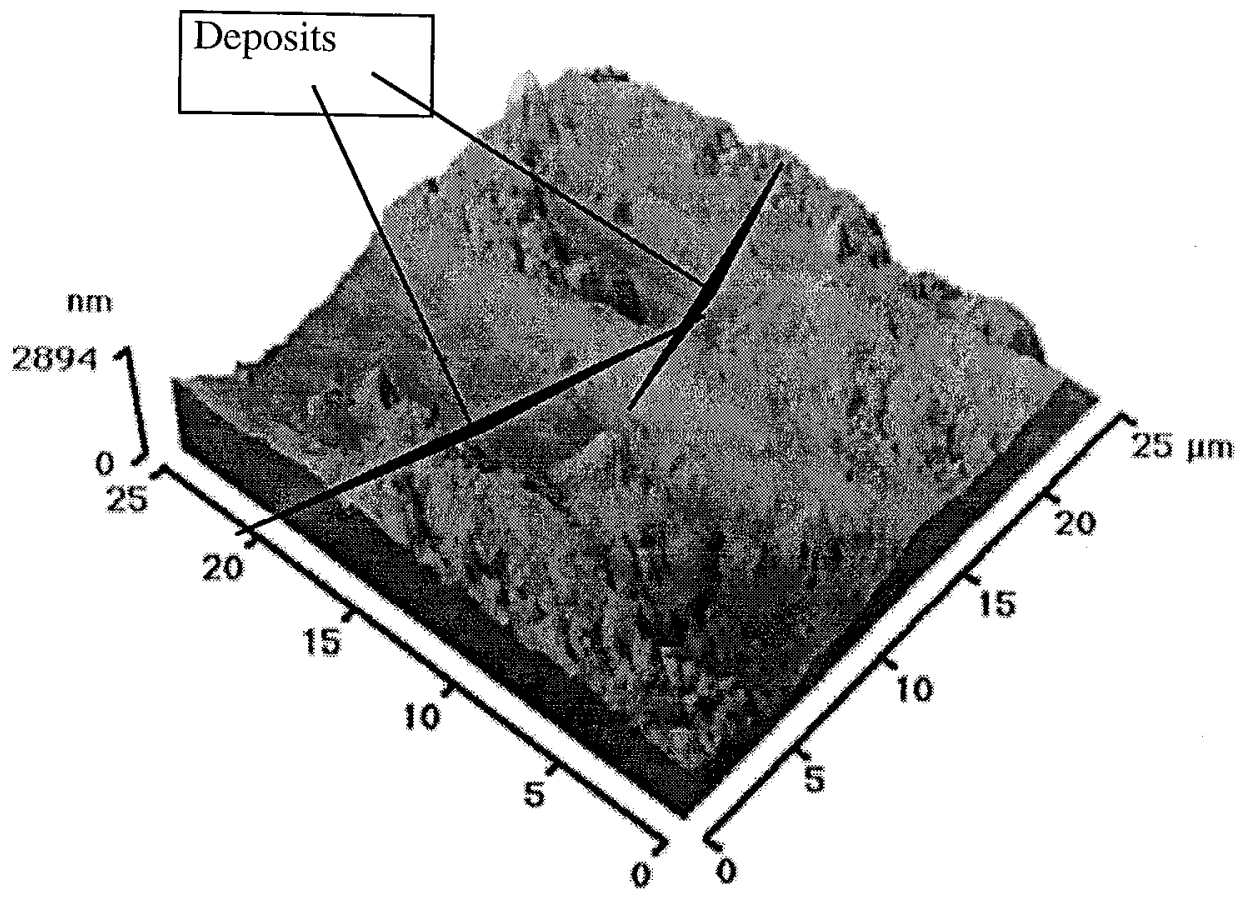

pb990607.054 AFM Image 


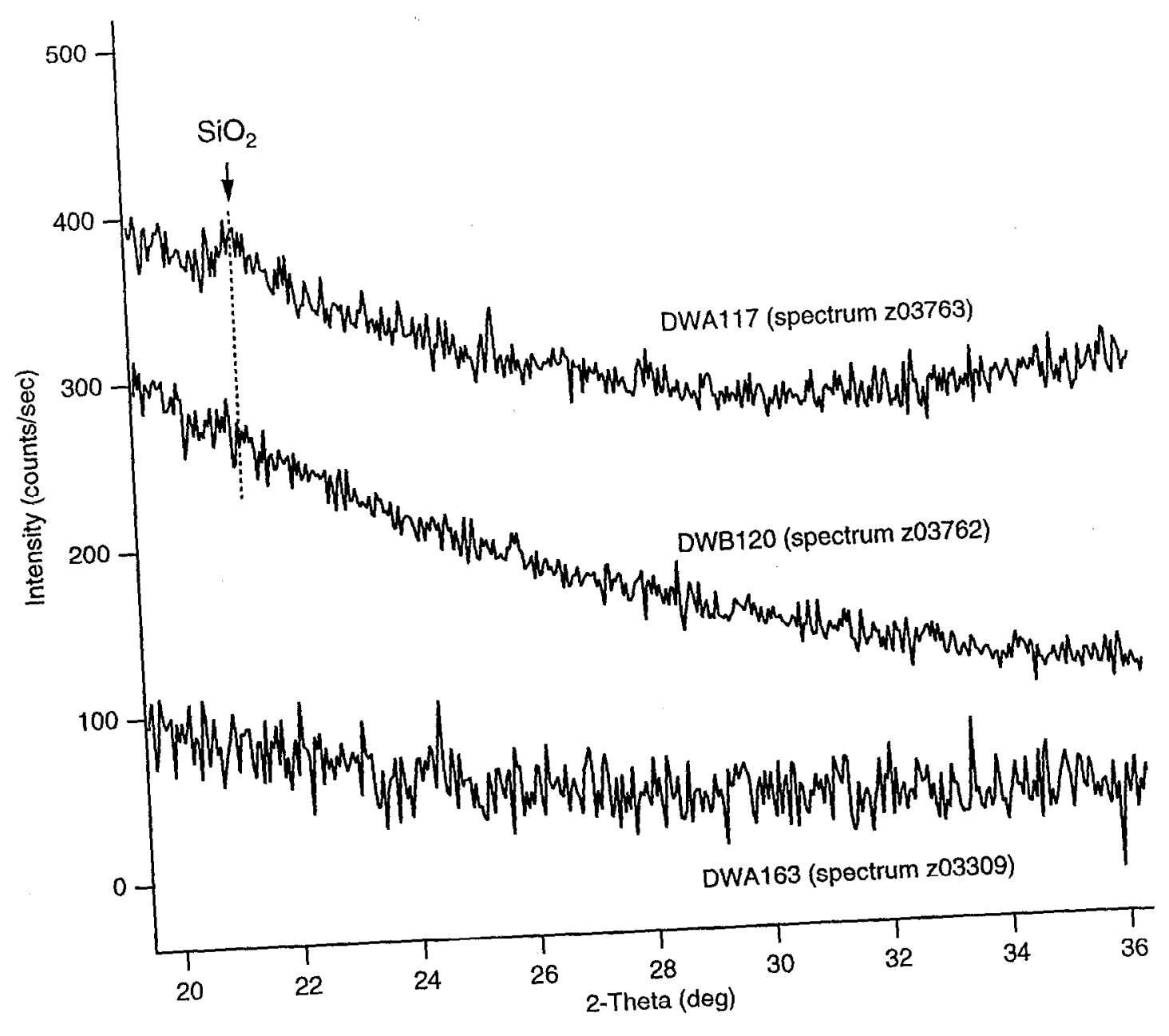

X-Ray Spectra of Scales on SCW Test Coupons 
DWA 120 (SCW, 90C, Aqueous)

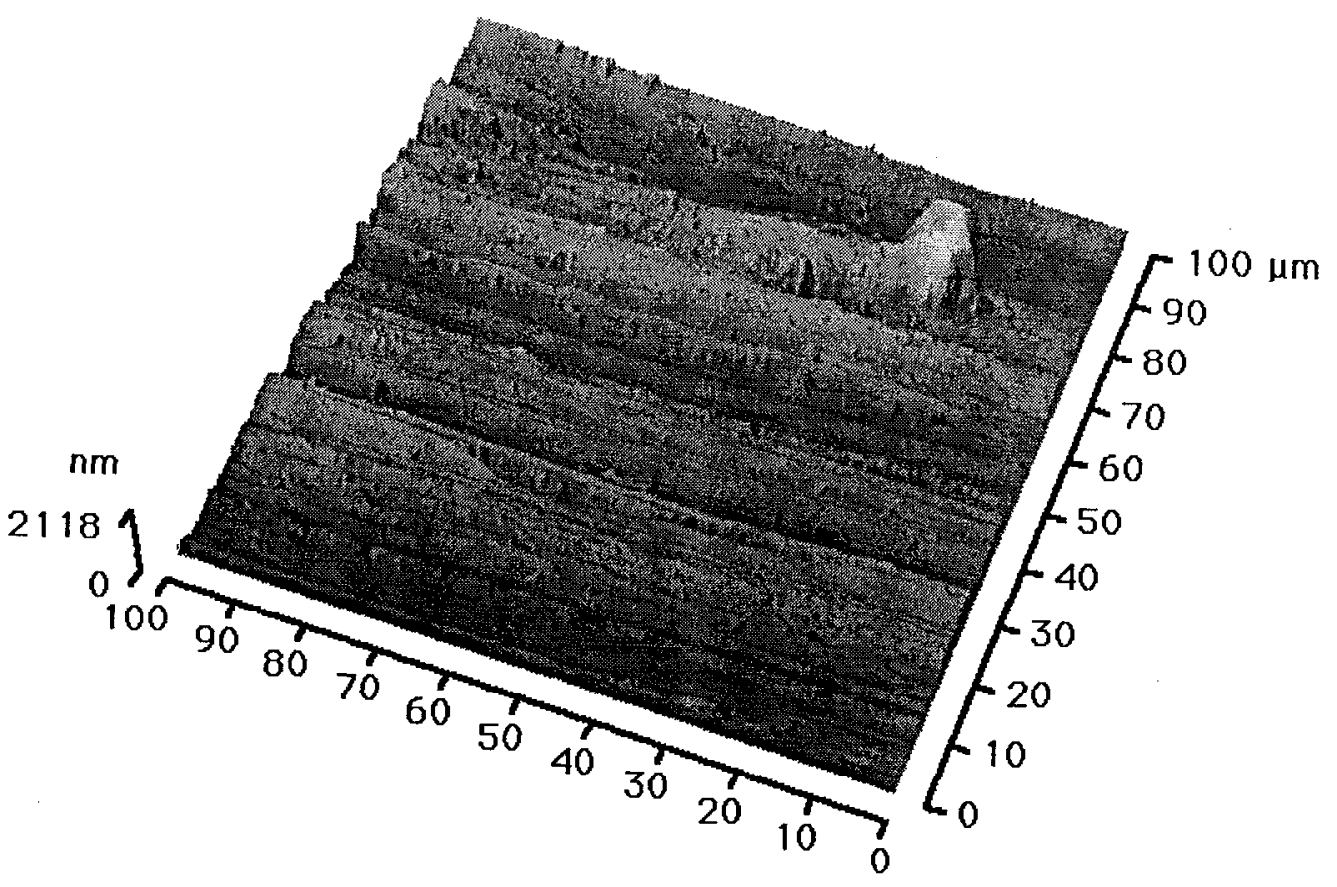

pb990607.001 AFM Image 


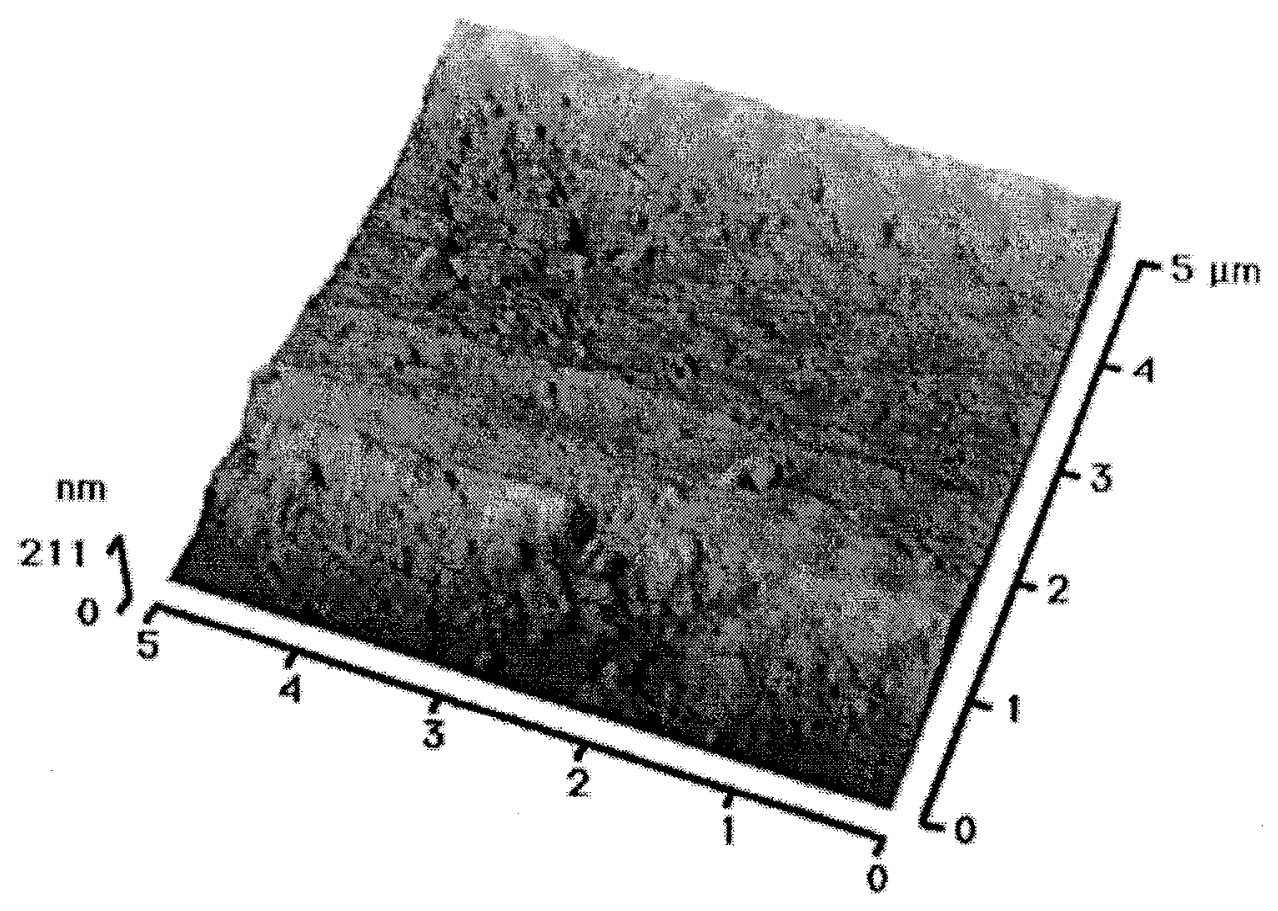

pb990607.005 AFM Image 


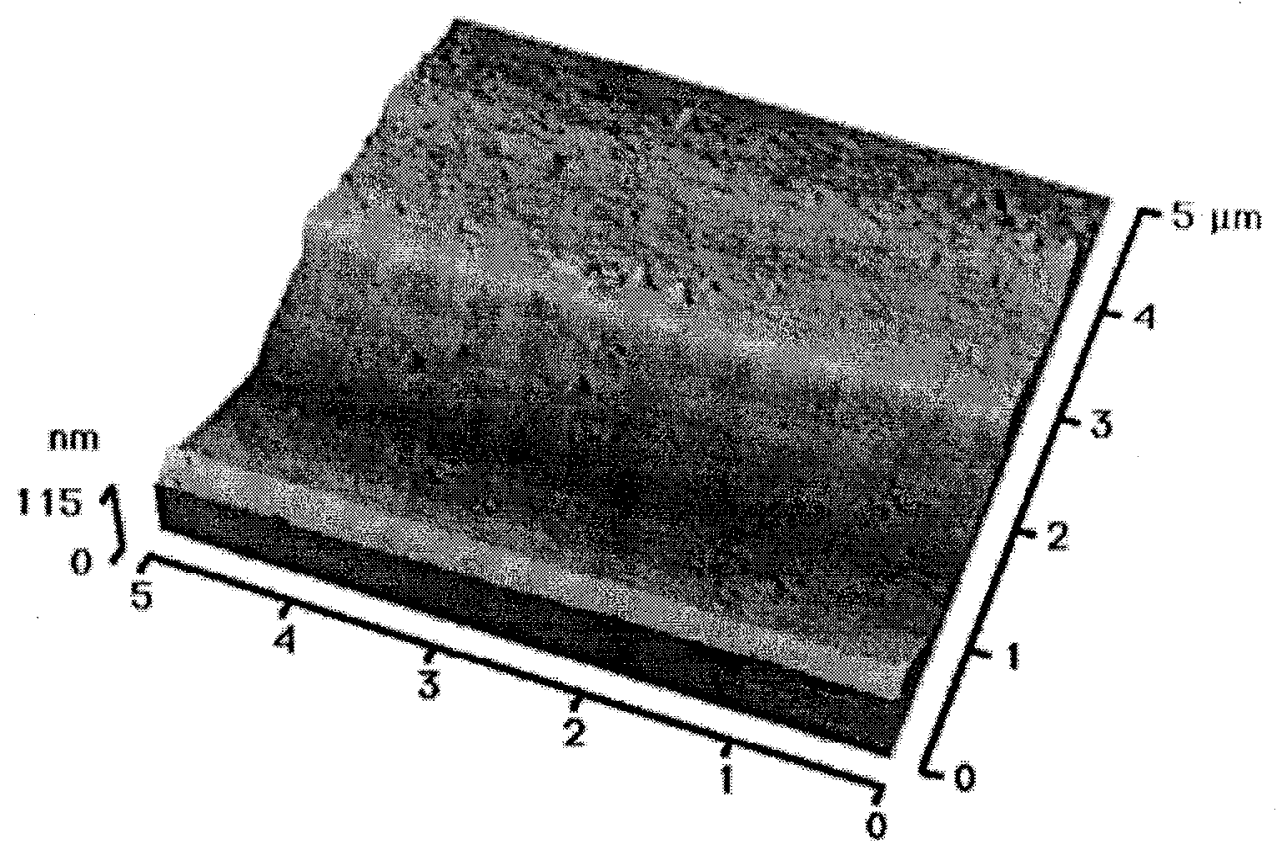

pb990607.015 AFM Image 


\section{DWA117 (SCW, 90C, Vapor)}

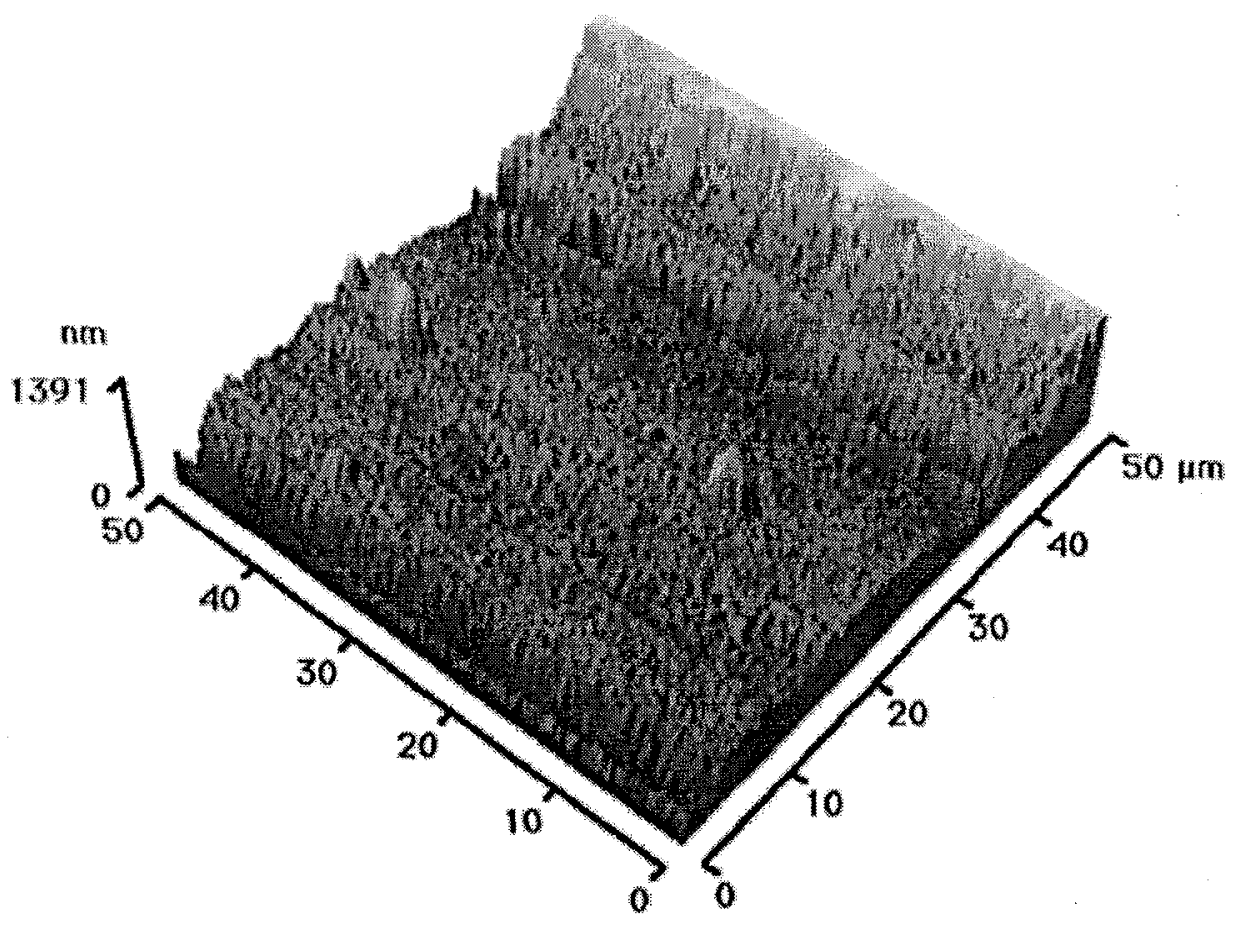

pb990607.039 AFM Image 


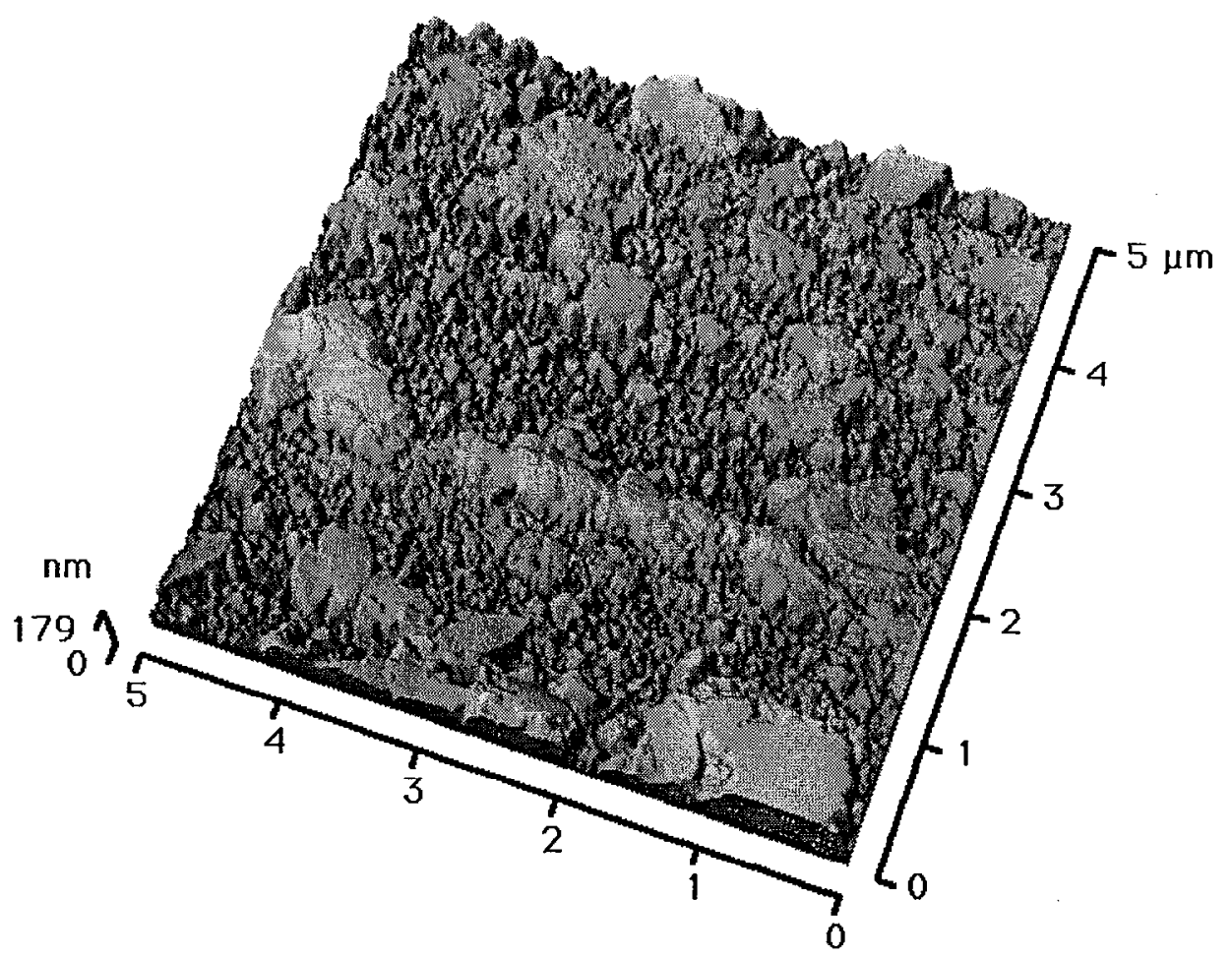

pb990607.035 AFM Image 


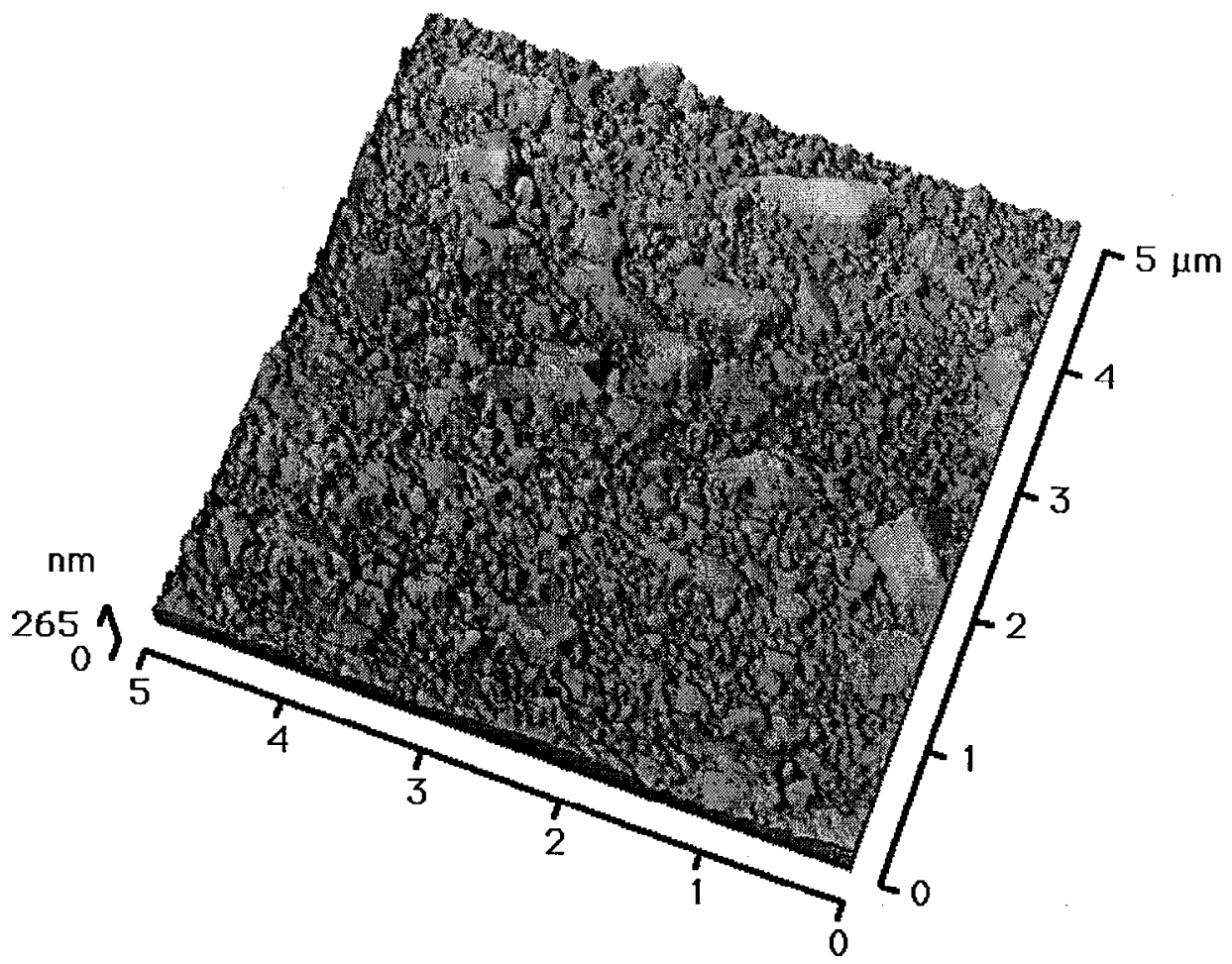

pb990607.037 AFM Image 


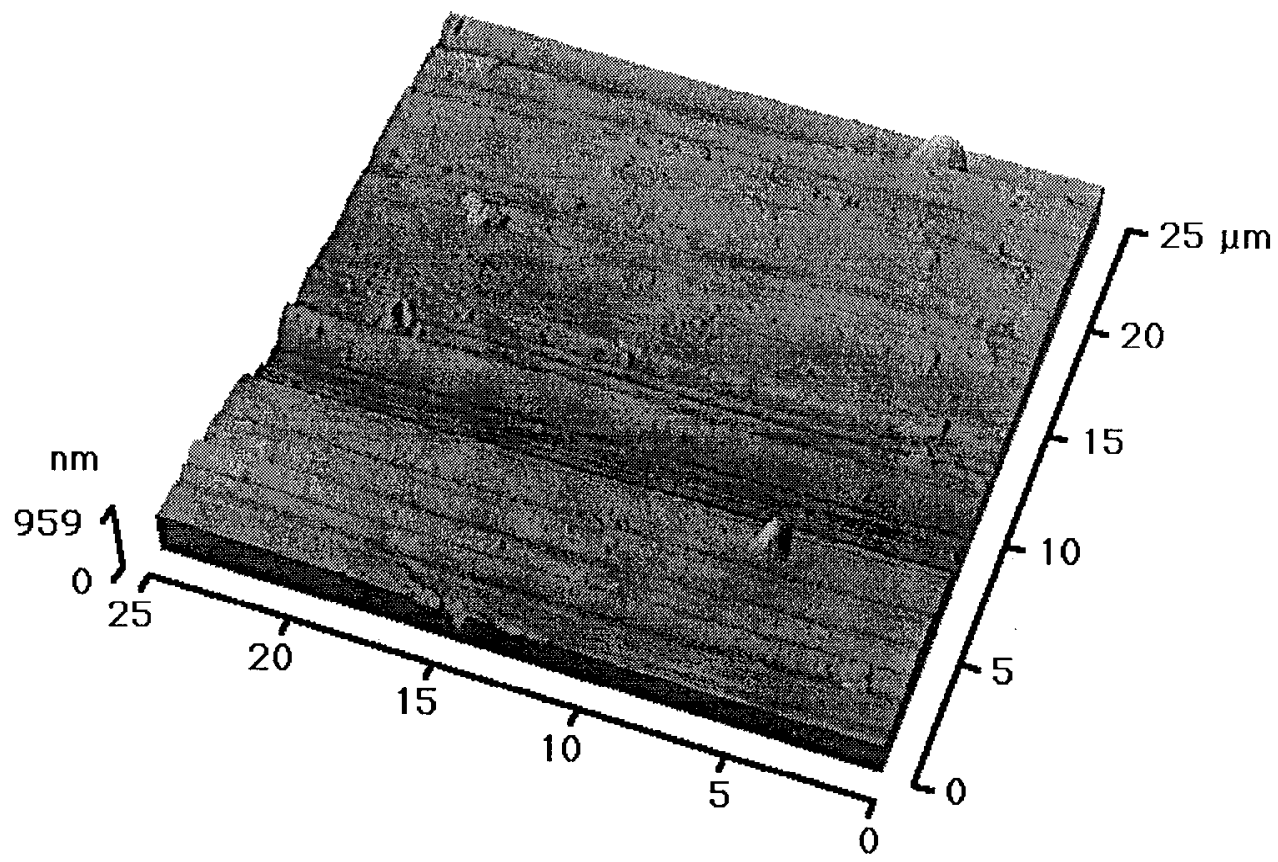

pb990607.044 AFM Image 


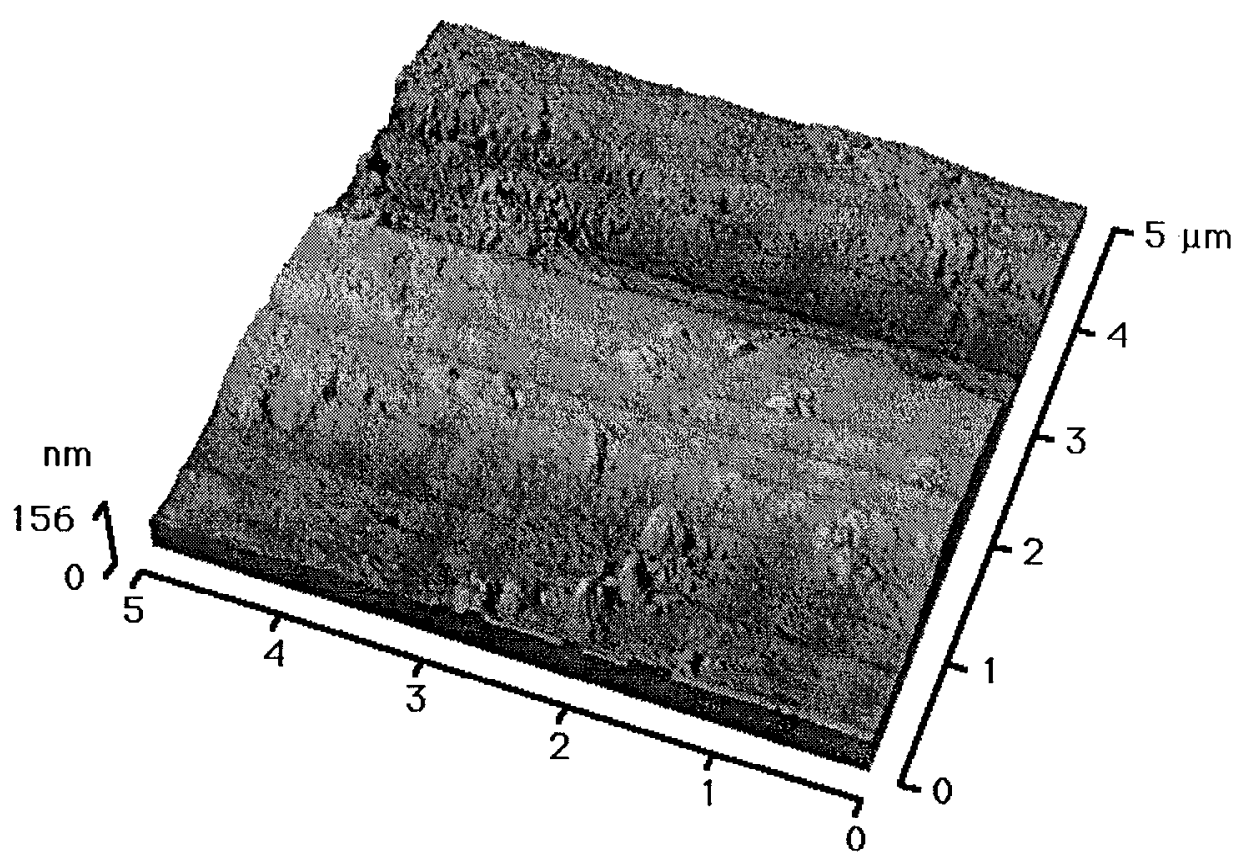

pb990607.041 AFM Image 


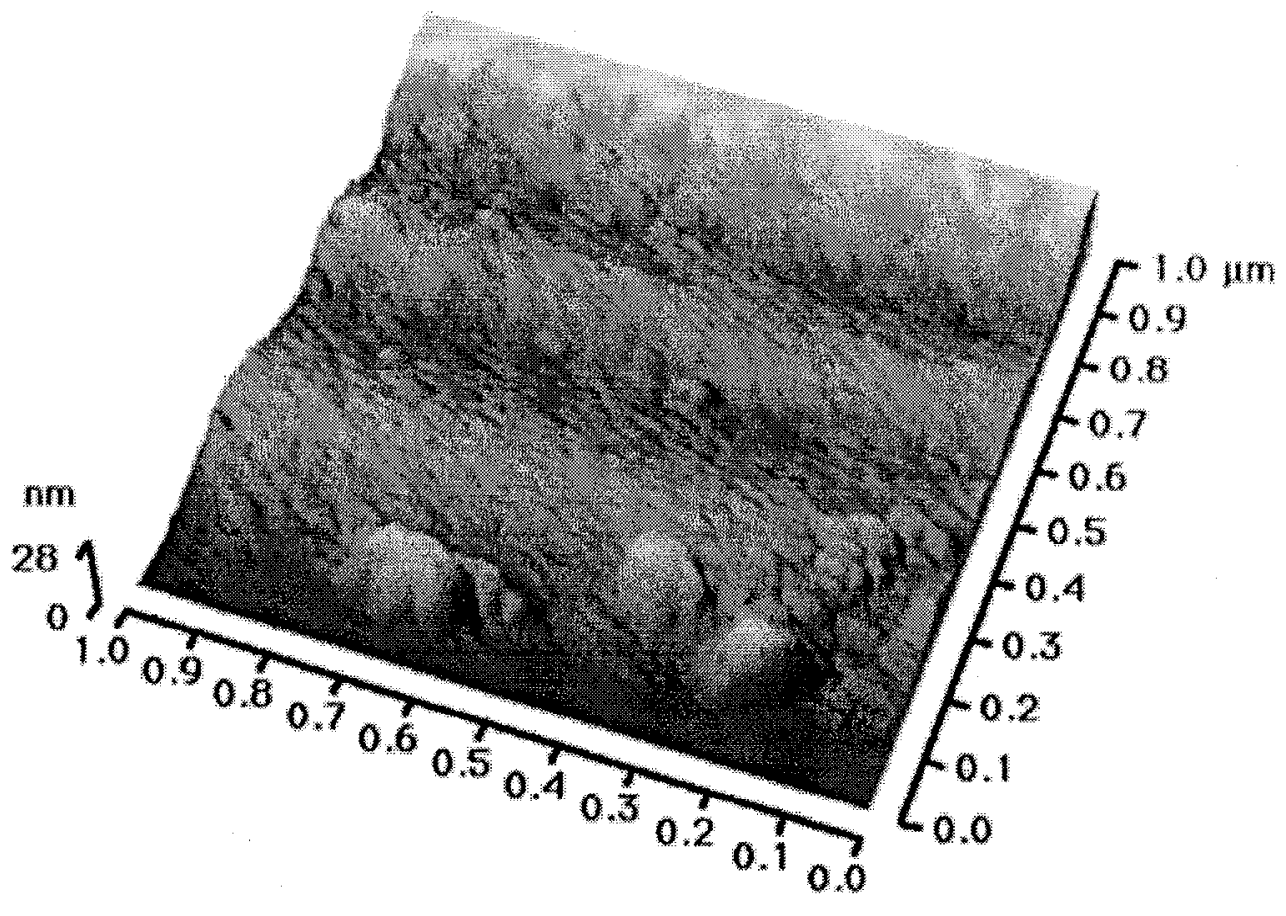

pb990607.042 AFM Image 
Proposal No. 9954/2506M

\title{
X-RAY WAVEGUIDES FOR HIGH RESOLUTION X-RAY ANALYSIS
}

\author{
Troy W. Barbee, Jr. \\ Lawrence Livermore National Laboratory \\ Livermore C $\Lambda 94550$ \\ Introduction \\ The ability to characterize crystallographic \\ and compositional distributions in macroscopic \\ material samples significant to DOE - relevant \\ materials as well as a more general class of \\ technologically important materials at sub-100-nm \\ resolution levels is not possible with traditional $\mathrm{x}$ - \\ ray technologies. This ability would offer the \\ materials community new understanding of \\ relationships among synthesis, structure, and \\ property and would enable materials engineering at \\ the mesoscopic-to-microscopic scales. \\ The project goals were to model, synthesize, \\ and characterize thin-film, $x$-ray waveguide \\ structures to determine whether such nanostructures \\ can be fabricated with the precision required for true \\ waveguide operation at x-ray energies. In FY98, we \\ designed, fabricated, and characterized (at the \\ Stanford Synchrotron Radiation Laboratory) \\ optimized, thin-film, X-ray waveguide structures \\ (XWGs) as resonant concentrators of $\mathrm{X}$-rays which \\ may be applied as diffraction-limited, linear x-ray \\ sources. We fabricated nine waveguide structures \\ that were optimized to operate in the cavity modes \\ $\mathrm{m}=1,2,3$ and tested them at $\mathrm{x}$-ray energies of 6 to \\ $10 \mathrm{keV}$. The observed performances were compared \\ to the calculations based on the design strucutres \\ and excellent agreement was demonstrated. \\ The LLNL LDRD project contained tasks as \\ presented in TABLE1. which include all aspects of \\ the development of these unique thin film $x$-rtay \\ optical devices. $\mathrm{X}$-ray waveguide designs were made \\ using a standard $\mathrm{x}$-ray multilayer $\mathrm{x}$-ray optic \\ Fresnel code. Materials were selected on the basis \\ incidence reflectivities and fluorescence as functions \\ of both $\mathrm{x}$-ray energy and grazing angle of incidence. \\ TABLE 1. \\ LLNL X-ray Waveguide Project \\ A.X-ray Waveguide A Cavity \\ Design/Model Calculations \\ 1. As a function of Cavity Structure \\ 2. As a function of Cavity Materials \\ 3. As a function of Wavelength \\ 4. As a function of Waveguide Mode

\section{B.X-ray Waveguide Cavity Fabrication \\ 1. Multilayer Synthesis process \\ 2. Substrates \\ 3. Preparation of the Cavity Termination Emitting Surface}

\section{X-ray Waveguide Cavity-Laboratory Characterization} \\ 1. X-ray Reflectivity/Fluorescence \\ a. LLNL Laboratory \\ b. Synchrotron \\ 2. LLNL SEM/TEM Structural Characterization
a. Plan View and Cross-Section View
b. Interfacial Structure \\ D. Waveguide Performance-Synchrotron \\ 1. As a function of Waveguide Structure \\ 2. As a function of Waveguide Materials \\ 3. As a function of Wavelength \\ 4. As a function of Waveguide Mode \\ 5. Comparison With Model Calculations
} of calculated performance as well as sputter deposition characteristics. Laboratory x-ray reflectivity measurements were made prior to the SSRL experimental run to assess the quality of the samples. Cross-section Transmission Electron Microscopy observations of selected sample were made to enable asssessment of the relationship between the design structures and the fabricated structures. The cross-section TEM observations corrrelated well with the waveguide fabricaiton parameters supporting the observed corrlations between the experimental and calculated grazing 